\title{
əThe Arctic Ocean Seasonal Cycles of Heat and Freshwater Fluxes: Observation-Based Inverse Estimates
}

\author{
Takamasa Tsubouchi, ${ }^{\mathrm{a}}$ Sheldon Bacon, ${ }^{\mathrm{a}}$ YeVgeny AKsenov, ${ }^{\mathrm{a}}$ \\ Alberto C. Naveira Garabato, ${ }^{\mathrm{b}}$ AgnieszKa BeszCZynska-Möller,${ }^{\mathrm{c}}$ EdMOnd Hansen,,${ }^{\mathrm{d} e}$ \\ LAURA DE STEur, ${ }^{\mathrm{d}}$ Beth Curry, ${ }^{\mathrm{f}}$ AND Craig M. LeE ${ }^{\mathrm{f}}$ \\ ${ }^{a}$ National Oceanography Centre, Southampton, United Kingdom \\ ${ }^{\mathrm{b}}$ University of Southampton, Southampton, United Kingdom \\ ${ }^{c}$ Physical Oceanography Department, Institute of Oceanology, Polish Academy of Sciences, Sopot, Poland \\ ${ }^{\mathrm{d}}$ Norwegian Polar Institute, Troms $\phi$, Norway \\ ${ }^{\mathrm{e}}$ Multiconsult, Troms $\varnothing$, Norway \\ ${ }^{\mathrm{f}}$ University of Washington, Seattle, Washington
}

(Manuscript received 13 November 2017, in final form 16 May 2018)

\begin{abstract}
This paper presents the first estimate of the seasonal cycle of ocean and sea ice heat and freshwater (FW) fluxes around the Arctic Ocean boundary. The ocean transports are estimated primarily using 138 moored instruments deployed in September 2005-August 2006 across the four main Arctic gateways: Davis, Fram, and Bering Straits, and the Barents Sea Opening (BSO). Sea ice transports are estimated from a sea ice assimilation product. Monthly velocity fields are calculated with a box inverse model that enforces mass and salt conservation. The volume transports in the four gateways in the period (annual mean \pm 1 standard deviation) are $-2.1 \pm 0.7 \mathrm{~Sv}$ in Davis Strait, $-1.1 \pm 1.2 \mathrm{~Sv}$ in Fram Strait, $2.3 \pm 1.2 \mathrm{~Sv}$ in the BSO, and $0.7 \pm$ $0.7 \mathrm{~Sv}$ in Bering Strait $\left(1 \mathrm{~Sv} \equiv 10^{6} \mathrm{~m}^{3} \mathrm{~s}^{-1}\right)$. The resulting ocean and sea ice heat and FW fluxes are $175 \pm 48 \mathrm{TW}$ and $204 \pm 85 \mathrm{mSv}$, respectively. These boundary fluxes accurately represent the annual means of the relevant surface fluxes. The ocean heat transport variability derives from velocity variability in the Atlantic Water layer and temperature variability in the upper part of the water column. The ocean FW transport variability is dominated by Bering Strait velocity variability. The net water mass transformation in the Arctic entails a freshening and cooling of inflowing waters by $0.62 \pm 0.23$ in salinity and $3.74^{\circ} \pm 0.76^{\circ} \mathrm{C}$ in temperature, respectively, and a reduction in density by $0.23 \pm 0.20 \mathrm{~kg} \mathrm{~m}^{-3}$. The boundary heat and FW fluxes provide a benchmark dataset for the validation of numerical models and atmospheric reanalysis products.
\end{abstract}

\section{Introduction}

The Arctic has experienced unprecedented climate change in the last few decades. Surface air temperature in the Arctic has risen more than twice as fast as the rest of the globe, a phenomenon known as "Arctic amplification" (Serreze et al. 2009). The September sea ice extent has steadily decreased since 1979 (Serreze et al. 2007a, 2016).

D Denotes content that is immediately available upon publication as open access.

Supplemental information related to this paper is available at the Journals Online website: https://doi.org/10.1175/JPO-D-17-0239.s1.

\footnotetext{
Corresponding author: Takamasa Tsubouchi, takamasa.tsubouchi@ uib.no
}

Russian river runoff has increased (Overeem and Syvitski 2010; Shiklomanov and Lammers 2014). Atlantic water (AW) temperature exhibited a warming signal in the $2000 \mathrm{~s}$ in Fram Strait (Beszczynska-Möller et al. 2012), offshore of the Laptev Sea (Polyakov et al. 2011), and in the central Arctic (Korhonen et al. 2013; Polyakov et al. 2012). Freshwater (FW) storage in the Canadian basin increased significantly during the 2000s (Proshutinsky et al. 2009; Giles et al. 2012; Rabe et al. 2014; Armitage et al. 2016), allied to acceleration of the Beaufort gyre circulation (McPhee et al. 2009; Giles et al. 2012; McPhee 2013; Armitage et al. 2017). Polyakov et al. (2017) identify what they call the encroaching "Atlantification" of the Eurasian basin as a developing process that is propelling the Arctic toward a new climate state, and they associate sea ice reduction, halocline weakening, shoaling of the AW layer, and increased winter ventilation with this process. 
Our understanding of the role of the ocean in the Arctic climate system is improving, but our knowledge of the fundamental physical fluxes of heat and freshwater remains poor (Mauritzen et al. 2011; Haine et al. 2015; Carmack et al. 2015, 2016). Even the long-term mean ocean heat transport across the Arctic boundary is unknown (Schauer and Beszczynska-Möller 2009; Carmack et al. 2015). For the ocean FW transport, decadal-average views based on different available data periods represent the state of the art (Dickson et al. 2007; Haine et al. 2015; Carmack et al. 2016). This basic deficiency is well illustrated by Cowtan and Way (2014); their Fig. 1a highlights starkly the sparsity of sustained surface temperature measurements over the Arctic Ocean. This sparsity applies to all other climate-relevant parameters in the region, such as wind speed and direction, humidity, evaporation, precipitation, and so on. A parallel problem exists with river runoff: the largest rivers are gauged, but $\sim 30 \%$ of total runoff is estimated to be ungauged (Lammers et al. 2007; Shiklomanov and Lammers 2009).

To begin to fill this knowledge gap, we have been developing the "control volume" approach to the calculation of Arctic ice and ocean fluxes of climaterelevant quantities. A control volume is a box that, in this case, comprises the Arctic Ocean, where the upper surface is either the surface of the open ocean or the upper surface of sea ice (as appropriate), the lower surface is the sea bed, and the sides comprise either land or ocean passages ("gateways"). With a control volume, simple conservation laws can be applied, using inverse methods, to measurements around the ice and ocean boundary of the box, in order to ensure conservation of mass and of salinity. The output is a mass- and salinityconserving ice and ocean boundary velocity field. This field then enables the calculation of surface fluxes of heat and FW, allowing for storage and release of those quantities within the control volume interior. The waters entering the Arctic are mainly warm and salty while those leaving are mainly cold and fresh; the net change in properties is caused by surface fluxes.

Quasi-synoptic ocean and sea ice heat and FW fluxes were calculated across the pan-Arctic boundary for summer 2005 by Tsubouchi et al. (2012, hereafter T2012). T2012 was the first paper to demonstrate the power of the control volume approach, by assembling measurements across the four main Arctic gateways-the Fram, Bering, and Davis Straits, and the Barents Sea Opening (BSO). Subsequent analysis used the T2012 boundary velocity field to generate baseline estimates of pan-Arctic fluxes of inorganic and organic nutrients (Torres-Valdés et al. 2013, 2016) and carbon (MacGilchrist et al. 2014).

Here we take a similar approach, but our aim now is to calculate the first annual-average values of Arctic ice and ocean boundary-and hence also of surface—heat and FW fluxes. The approach is made possible by the sustained presence in the four main Arctic gatewaysthe Fram, Bering, and Davis Straits, and the BSO-of moored instrumentation measuring temperature, salinity and velocity. In combination, as an Arctic Ocean boundary array, they represent an underutilized resource for the estimation of Arctic surface fluxes. The objectives of this study are, therefore, 1) to generate for the first time a time series of 12 monthly piecewisecontinuous estimates of the boundary components of net (surface) fluxes of heat and freshwater, in order to expose the seasonality inherent in that component, and also 2) to examine the extent to which the assessment quality is dependent on the quantity and distribution of the available measurements.

This paper is structured as follows. We present our data and methods in section 2 and our results in section 3, and in section 4 we provide a discussion and interpretation of the results. Section 5 is a summary.

\section{Data and methods}

In this section, we first describe our measurement and model output resources; then we describe the method by which a year-long time series of gridded property and velocity fields is generated; third, we set out a brief overview of the box inverse model; finally, we describe the method of heat and FW flux calculation.

\section{a. Hydrographic data and numerical model outputs}

Our main data source is 138 moored instruments deployed in the Arctic four main gateways from summer 2005 to summer 2006. Moored instrument locations (41 mooring sites) and the positions in the water column of the 138 instruments are shown in Fig. 1. Instruments comprise temperature- and salinity-measuring devices, acoustic Doppler current profilers (ADCPs), and singlepoint current meters. Table 1 summarizes the moored instruments analyzed in this study. In the gateways, the following moored data are analyzed: 39 moored instruments [21 MicroCATs, 9 recording current meters (RCMs), and 9 ADCPs] in Davis Strait from 1 September 2005 to 30 September 2006 (Curry et al. 2014); 17 moored instruments (5 MicroCATs and 12 RCMs) in the western part of Fram Strait from 5 September 2005 to 3 September 2006 (de Steur et al. 2014); and 60 moored instruments (16 MicroCATs and 44 RCMs) in the central and eastern parts of Fram Strait from 26 August 2005 to 26 August 2006 (Budéus et al. 2008). In the BSO, data come from 13 moored instruments (11 RCMs and 2 ADCPs) from 18 August 2004 to 29 June 2007 (Ingvaldsen et al. 2004); 4 moored 

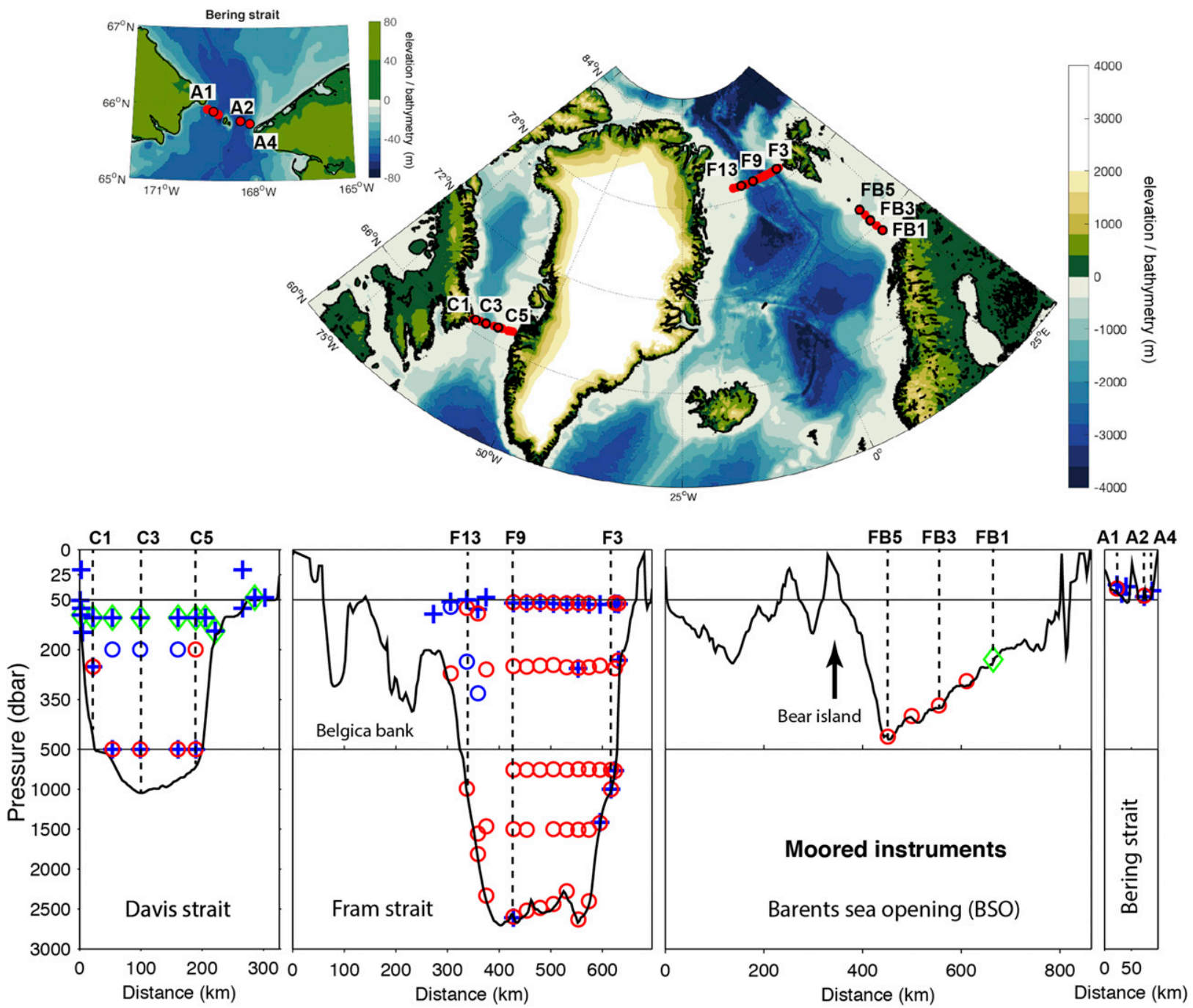

FIG. 1. (top) Mooring locations (red circles) in Davis Strait, Fram Strait, the Barents Sea Opening (BSO), and Bering Strait analyzed in this study. A few mooring sites are labeled and highlighted by black circles. Elevation and bathymetric data are based on ETOPO2v2 (National Geophysical Data Center 2006). (bottom) Location of 138 mooring instruments across the pan-Arctic boundary section. SeaBird MicroCAT measuring temperature and salinity are shown as blue crosses. Aanderaa single point current meters measuring temperature and velocity are shown as red circles. When the current meter also measures salinity and the observed salinities are analyzed in this study, the positions of current meters are shown as blue circles. Green diamonds show the locations of the ADCPs, measuring vertical velocity profiles.

instruments (3 MicroCATs and $1 \mathrm{RCM}$ ) on the Russian side of the Bering Strait from 20 August 2005 to 24 August 2006 (Smolin et al. 2006); and 5 moored instruments (3 MicroCATs and 2 RCMs) on the U.S. side of the Bering Strait from 11 July 2005 to 31 August 2006 (Woodgate 2006). In Davis Strait, processed daily data are analyzed instead of data at the original sampling intervals (Curry et al. 2014). A total of 138 moored instrument records (46 MicroCATs, 81 RCMs, and 11 ADCPs) are combined between 5 September 2005 and 24 August 2006.

Nine CTD sections, occupied nearly monthly between Bear Island and Norway in the BSO, are also analyzed.
For each section, mean station spacing is $30 \mathrm{~km}$ with 1-dbar vertical resolution. A typical section comprises 20 stations. The hydrographic data are downloaded from the International Council for the Exploration of the Sea database (http://www.ices.dk/).

The Nucleus for European Modeling of the Ocean (NEMO) is a widely used framework for oceanographic modeling. Bacon et al. (2015) describe the model configuration and forcing. The model's tripolar grid concentrates resolution in the Arctic, so that the $1 / 12^{\circ}$ configuration used here has effective horizontal resolution around the defined boundary of $\sim 4-5 \mathrm{~km}$. Model output is available 
TABLE 1. Moored instruments analyzed in this study and length of data (latest starting date and earliest end date); numbers of moored instruments in each gateway are shown as categorized by type of instruments (MicroCAT, RCMs, and ADCP).

\begin{tabular}{|c|c|c|c|c|c|c|}
\hline Straits & Start date & End date & MicroCAT & $\mathrm{RCM}$ & $\mathrm{ADCP}$ & Total \\
\hline Davis & 1 Sep 2005 & 30 Sep 2006 & 21 & 9 & 9 & 39 \\
\hline Fram west & 5 Sep 2005 & 3 Sep 2006 & 5 & 12 & 0 & 17 \\
\hline Fram central/east & 26 Aug 2005 & 26 Aug 2006 & 16 & 44 & 0 & 60 \\
\hline \multirow[t]{3}{*}{ BSO } & 18 Aug 2004 & 15 Sep 2005 & 0 & 5 & 0 & 5 \\
\hline & 15 Sep 2005 & 17 Jun 2006 & 0 & 3 & 1 & 4 \\
\hline & 18 Jun 2006 & 29 Jun 2007 & 0 & 3 & 1 & 4 \\
\hline Bering Russia & 20 Aug 2005 & 24 Aug 2006 & 3 & 1 & 0 & 4 \\
\hline \multirow[t]{2}{*}{ Bering United States } & 11 Jul 2005 & 15 Jul 2006 & 2 & 1 & 0 & 3 \\
\hline & $12 \mathrm{Jul} 2006$ & 31 Aug 2007 & 1 & 1 & 0 & 2 \\
\hline All straits & 5 Sep 2005 & 24 Aug 2006 & 48 & 79 & 11 & 138 \\
\hline
\end{tabular}

as 5-day mean fields of ocean temperature, salinity, and velocity. It has 75 layers in the vertical, of which there are 24 layers in the upper $100 \mathrm{~m}, 11$ layers between 100 and $300 \mathrm{~m}, 25$ layers between 300 and $3000 \mathrm{~m}$, and 15 layers below $3000 \mathrm{~m}$. We use model output to patch in data in regions where observations are lacking (Belgica Bank, Bjørnøya Bank, and the water above the shallowest instruments). The model output is available at http:/gwsaccess.ceda.ac.uk/public/nemo/. The model's credibility in the Arctic context has been established in a number of studies, for example: Atlantic water inflow (Aksenov et al. 2010a; Lique and Steele 2013), polar water outflow (Aksenov et al. 2010b; Lique et al. 2010), the Arctic boundary current (Aksenov et al. 2011), and the East Greenland Coastal Current (Bacon et al. 2014).

Monthly sea ice thickness, velocity, and temperature are obtained from the Pan-Arctic Ice Ocean Modeling and Assimilation System (PIOMAS; Zhang and Rothrock 2003). Schweiger et al. (2011) estimate PIOMAS sea ice thickness uncertainty to be $0.2 \mathrm{~m}$. The sea ice thickness $(\mathrm{m})$, sea ice velocity $\left(\mathrm{m} \mathrm{s}^{-1}\right)$, and surface temperature $\left({ }^{\circ} \mathrm{C}\right)$ data are downloaded from the Polar Science Centre at the University of Washington (UW) (http://psc.apl.uw.edu/research/projects/arctic-seaice-volume-anomaly/). Note that ice concentration is included in the calculation of sea ice thickness at a given point by PIOMAS output.

\section{b. Construction of 5-day temperature, salinity, and velocity gridded sections}

We choose to project the mooring records and CTD measurements in the BSO onto the same temporal resolution as NEMO. Therefore, we first need to establish a common ( 5 day) time base for the moored measurements. Our common time series starts at 1200 UTC 30 August 2005 and ends at 1200 UTC 4 September 2006.

With all instrumental records on a continuous 5-day time base, initial coast-to-coast and sea-bed-to-surface fields of temperature, salinity, and cross-sectional velocity are created. The horizontal grid resolution is $3 \mathrm{~km}$, considering the $1 / 12^{\circ}$ NEMO's horizontal resolution of $4-5 \mathrm{~km}$ in the Arctic gateway regions. The vertical grid resolution is 75 layers, the same as NEMO's. We add variability information above the shallowest moored instruments and across shelf regions using NEMO output. The area of vertical boundary is $10.51 \times 10^{8} \mathrm{~m}^{2}$, and the surface area inside the boundary is $1.13 \times 10^{13} \mathrm{~m}^{2}$ (Jakobsson 2002). The mooring and CTD measurements cover a vertical ocean area of $9.72 \times 10^{8} \mathrm{~m}^{2}$, or $92 \%$ of the total. The area patched by model output is $0.79 \times 10^{8} \mathrm{~m}^{2}, 8 \%$ of the total. The details of mooring data availability and treatment and gridding procedure can be found in the online supplemental material in section A.

\section{c. Box inverse model}

The first application of inverse methods to physical oceanography was by Wunsch (1978), who addressed the classical problem of determining the reference level velocity, which must be added to the thermal wind velocity to give the absolute velocity. Since then, the method has been commonly used to estimate the ocean circulation and transports (e.g., Mauritzen 1996; Bacon 1997; Ganachaud and Wunsch 2003; Lumpkin and Speer 2003; McDonagh and King 2005). One of the strengths of the method is its flexibility: any prior knowledge can be incorporated as a constraint, and the method can be adapted to estimate a variety of unknown aspects of the circulation. Additional types of unknowns have been incorporated, such as diapycnal velocity (McIntosh and Rintoul 1997), surface heat and FW fluxes (Mauritzen 1996; Lumpkin and Speer 2003; Naveira Garabato et al. 2003), and eddy-induced transports (Jullion et al. 2014).

For the Arctic Ocean box model inversion, developed in T2012, full-depth and layer-specific conservation of mass and salt (expressed in terms of volume and salinity, 
TABLE 2. Definitions of five model layers and corresponding water masses. The five model layers are the Surface Water (SURF) layer, Upper AW (UAW) layer, Atlantic Water (AW) layer, Intermediate Water (IW) layer, and Deep Water (DW) layer. The terms $\sigma_{0}$, $\sigma_{0.5}, \sigma_{1.0}$ show potential density relative to $0 \mathrm{dbar}, 500 \mathrm{dbar}$ and $1000 \mathrm{dbar}$, respectively. Depths of the lower interface (mean $\pm 1 \mathrm{std}$ ) are also shown.

\begin{tabular}{clccr}
\hline \hline Model layer & Layer group & Upper interface & Lower interface & Depth of lower interface \\
\hline 1 & SURF & Surface & $27.10 \sigma_{0}$ & $97 \pm 58 \mathrm{~m}$ \\
2 & UAW & $27.10 \sigma_{0}$ & $27.50 \sigma_{0}$ & $137 \pm 132 \mathrm{~m}$ \\
3 & AW & $27.50 \sigma_{0}$ & $30.28 \sigma_{0.5}$ & $375 \pm 118 \mathrm{~m}$ \\
4 & IW & $30.28 \sigma_{0.5}$ & $32.75 \sigma_{1.0}$ & $902 \pm 246 \mathrm{~m}$ \\
5 & DW & $32.75 \sigma_{1.0}$ & Bottom & N/A \\
6 & Full depth & Surface & Bottom & N/A \\
\hline
\end{tabular}

respectively) are enforced within specified uncertainties to determine four types of unknowns: reference velocity, diapycnal velocity, sea ice advection speed, and surface FW flux. The box inverse model in this study is based on that used by T2012.

We define five layers bounded by isopycnal surfaces (Table 2): the Surface Water (SURF) layer, Upper Atlantic Water (UAW) layer, Atlantic Water (AW) layer, Intermediate Water (IW) layer, and Deep Water (DW) layer. Water mass definitions are the same as in T2012, with one change: we now define Surface Water as the combination of T2012's two uppermost layers (Surface Water and Subsurface Water). Settings of the box inverse model used in this study are provided in appendix A.

The 5-day mean fields within corresponding calendar months are averaged to obtain 12 monthly fields. In reality, 5-day mean fields are converted into eleven 30-day $(6 \times 5$-day time step) months plus one 35 -day (7 $\times 5$-day time step) month, equivalent to July 2006 . The box inverse model is applied to 12 individual months to quantify the time variability of horizontal boundary fluxes of volume, heat and FW.

There are five differences between this study and T2012. First, we constrain mass and salt, instead of mass and salt anomaly. Second, we use a sea ice data assimilation product (PIOMAS) to obtain an observationbased, continuous estimate of sea ice exports across the four main gateways. Third, the use of NEMO model output is more extensive because the moored measurements reach neither the coasts nor the sea surface. In particular, two wide banks lack measurementsBelgica Bank, off northeast Greenland, and Bjørnøya Bank, between Bear Island and Svalbard-and the shallowest instruments lie (for practical reasons) between 50- and 100-m water depth. Fourth, T2012 was a quasi-synoptic study using measurements made from ships (albeit within the same period of about a month) whereas this study is synoptic, employing a calendar year of continuous, simultaneous marine measurements.
Fifth, T2012 used CTD measurements with high spatial resolution ( $1 \mathrm{~m}$ in vertical and $5-30 \mathrm{~km}$ in horizontal), whereas here the spatial resolution is determined by the moored instrument locations (typically $50-500 \mathrm{~m}$ in vertical and $30-200 \mathrm{~km}$ in horizontal).

\section{d. Heat and FW transport calculation, reference values, and uncertainties}

We present the equations that determine the relationships between the surface fluxes of heat and FW and those fluxes at the ice and ocean boundary, including storage inside the control volume, as presented in Bacon et al. (2015). However, in this study, we do not calculate the storage fluxes explicitly. For detailed consideration of the meaning of our results in this context, see section $4 \mathrm{a}$ below. For FW fluxes,

$$
F_{\mathrm{FW}}^{\mathrm{surf}}=\frac{1}{\bar{S}} \iint\left[\left(v^{\prime} S^{\prime}\right)^{o}+\left(v^{\prime} S^{\prime}\right)^{i}\right] d x d z+F_{\mathrm{FW}}^{\mathrm{stor}},
$$

where $F_{\mathrm{FW}}^{\text {surf }}$ is the surface $\mathrm{FW}$ flux and $F_{\mathrm{FW}}^{\text {stor }}$ is $\mathrm{FW}$ storage change in time within the boundary; superscripts $o$ and $i$ refer to liquid ocean and sea ice, respectively; $v^{\prime}$ is the cross-section velocity anomaly about the mean $\bar{v} ; z$ is depth and $x$ is the along-boundary coordinate; and $S^{\prime}$ is the salinity difference from its reference value $\bar{S}$. Note that $\bar{v}$ is not zero. It is a small number $\left[O\left(10^{-4}\right) \mathrm{m} \mathrm{s}^{-1}\right]$, which balances with surface flux and storage term in the mass conservation. As discussed by T2012 and Bacon et al. (2015), $\bar{S}$ is the area weightedmean salinity across the section for each month. Ocean FW transport and sea ice FW transport are calculated with reference to $\bar{S}$ for each month. Here $\bar{S}$ is $34.67 \pm 0.02$ (annual mean $\pm 1 \mathrm{std}$ ), and the 12 monthly values are $34.67,34.64,34.63$, 34.63, 34.66, 36.67, 34.68, 34.68, 34.70, $34.68,34.67$, and 34.66 during September 2005-August 2006. Sea ice salinity is set as 6 throughout the year because PIOMAS does not calculate sea ice salinity. The sea ice salinity 6 is close to first-year sea ice salinity (Kovacs 1996; Shokr and Sinha 2015). 
For heat fluxes,

$$
\begin{aligned}
F_{H}^{\mathrm{surf}}= & -\iint\left[\rho_{o} c_{p}^{o}\left(v^{\prime} \theta^{\prime}\right)^{o}+\rho_{i} c_{p}^{i}\left(v^{\prime} \theta^{\prime}\right)^{i}+\rho_{i} c_{f}(v)^{i}\right] d x d z \\
& +F_{H}^{\mathrm{stor}}
\end{aligned}
$$

where $F_{H}^{\text {surf }}$ is surface heat flux and $F_{H}^{\text {stor }}$ is heat storage change in time within the boundary; $\rho_{o}$ is density of seawater $\left(1027 \mathrm{~kg} \mathrm{~m}^{-3}\right), c_{p}^{o}$ is specific heat capacity of seawater $\left(3.987 \times 10^{3} \mathrm{~J} \mathrm{~kg}^{-1} \mathrm{~K}^{-1}\right), \rho_{i}$ is density of sea ice $\left(930 \mathrm{~kg} \mathrm{~m}^{-3}\right), c_{p}^{i}$ is specific heat capacity of sea ice, $c_{f}$ is latent heat of freezing $\left(3.347 \times 10^{5} \mathrm{~J} \mathrm{~kg}^{-1}\right), v$ is crosssectional velocity, and $\theta^{\prime}$ is the potential temperature difference from its reference value. By analogy with the FW transport calculation, ocean temperature transport and sea ice sensible heat transport are calculated with reference to the appropriate boundary-mean potential temperature for each month. The annual mean $( \pm 1 \mathrm{std})$ is $1.01^{\circ} \pm 0.16^{\circ} \mathrm{C}$, and the 12 monthly values are $1.26^{\circ}, 1.15^{\circ}$, $1.01^{\circ}, 0.91^{\circ}, 0.94^{\circ}, 0.91^{\circ}, 0.83^{\circ}, 0.82^{\circ}, 0.88^{\circ}, 0.99^{\circ}, 1.15^{\circ}$, and $1.24^{\circ} \mathrm{C}$ for September 2005-August 2006. Annual mean ( $\pm 1 \mathrm{std})$ sea ice temperature is $-11.6^{\circ} \pm 8.9^{\circ} \mathrm{C}$, with maximum $-0.54^{\circ} \mathrm{C}$ in July 2006 and minimum $-25.29^{\circ} \mathrm{C}$ in February 2006, obtained from PIOMAS monthly output over the Belgica Bank region $\left(78^{\circ}-80^{\circ} \mathrm{N}\right.$, $\left.17^{\circ}-6^{\circ} \mathrm{W}\right)$. Sea ice specific heat capacity is obtained from Table 2 in Ono (1967); maximum $2.92 \times 10^{4} \mathrm{~J} \mathrm{~kg}^{-1} \mathrm{~K}^{-1}$ for July 2006 and minimum $3.35 \times 10^{3} \mathrm{~J} \mathrm{~kg}^{-1} \mathrm{~K}^{-1}$ for February 2006. Sea ice density is fixed as $930 \mathrm{~kg} \mathrm{~m}^{-3}$.

As widely recognized, most ocean heat and FW transports are sensitive to the choice of reference values. Their effect on ocean heat transport is demonstrated in Schauer and Beszczynska-Möller (2009), and that on ocean FW transport is discussed in T2012 and Bacon et al. (2015). Following T2012, we choose reference values as boundary mean values in order to accurately diagnose air-sea fluxes from the observed boundary ocean and ice fluxes.

We make a practical distinction between ocean heat transport and ocean temperature transport. We refer to a quantity as temperature transport when it is sensitive to choice of reference temperature. We refer to a quantity as heat transport when it is not sensitive to choice of reference temperature. Following Talley (2003), the two quantities are distinguished (for clarity) through their units: we use watts (as usual) for heat transport, and we introduce the watt-equivalent (W-eq). for temperature transport. By analogy, ocean FW transports are also distinguished depending on their sensitivity to choice of reference salinity through their units of milli-Sverdrups (mSv) and mSv-equivalent (mSv-eq), following Talley (2008).
Finally, we present two different types of uncertainty. One is the temporal variability of a quantity over a given period, presented as one standard deviation (std) of the relevant time series. The other is uncertainty as quantification by sensitivity tests or other estimation method. To distinguish two different types explicitly, we always add italic labels ( \pm uncertainty) when quoting "sensitivity" uncertainties and sometimes add plain labels ( \pm 1 std) for std.

\section{Results}

In this section, we first illustrate the 5-day mean fields of temperature, salinity, and velocity in terms of annualmean values and variability at a selected depth. Next we consider the mass- and salt-conserved velocity fields and their horizontal and diapycnal volume transports; third are temperature and heat transports, and fourth are FW transports. Fifth, we present the results of a suite of sensitivity studies directed at understanding the impact of the NEMO model output on the results. Finally, we consider the transport-weighted mean temperature, salinity, and density of inflows and outflows and the associated net water mass transformation.

\section{a. Five-day mean gridded sections}

Figure 2a shows temperature variability at $50-\mathrm{m}$ depth. Regarding the seasonal cycle, substantial variability is observed in Bering Strait (from $-2^{\circ}$ to $8^{\circ} \mathrm{C}$ ), the eastern side of Davis Strait (from $-2^{\circ}$ to $6^{\circ} \mathrm{C}$ ), the east of Fram Strait $\left(4^{\circ}-7^{\circ} \mathrm{C}\right)$, and south of Bear Island in the $\mathrm{BSO}\left(5^{\circ}-9^{\circ} \mathrm{C}\right)$; these are all inflow regions. In contrast, in outflow regions (western Davis Strait and western Fram Strait including Belgica Bank), the temperature remains low throughout the year. Figure $2 b$ shows salinity variability at 50-m depth. It is notable that relatively fresh regions exhibit the highest seasonal variability: the outflows in Davis Strait and in the west of Fram Strait, and also the Bering Strait inflow. AW inflow salinities are relatively stable through the year.

Figure 2c shows the cross-section velocity at 50-m depth. Annual averaged values capture the major currents around the boundary. In Davis Strait, this includes the outflow in the west and inflow in the east. In Fram Strait, the major currents are the northward current near the Greenland coast, the anticyclonic circulation over Belgica Bank, the East Greenland Current (EGC) outflow, and the West Spitsbergen Current (WSC) inflow. The northward current near the Greenland coast is measured by hydrographic and mooring observations (Bourke et al. 1987; Topp and Johnson 1997; Schaffer et al. 2017). In the BSO, there is a variable outflow just south of Bear Island, and inflows in the main portion of 
(a) Temperature $\left({ }^{\circ} \mathrm{C}\right)$ at $50 \mathrm{~m}$

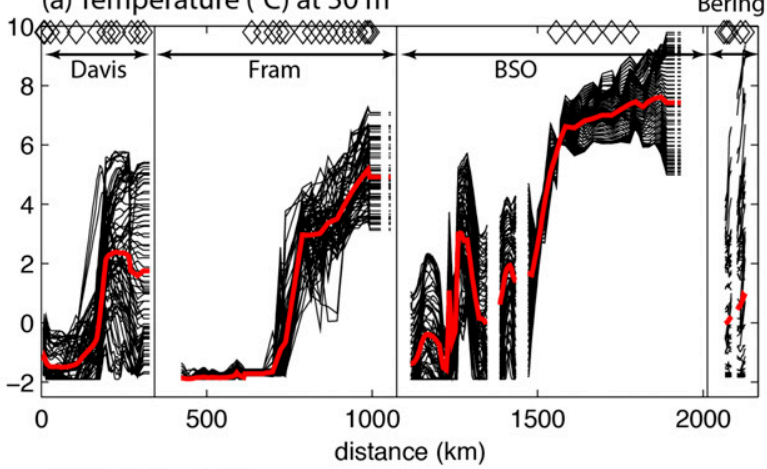

(b) Salinity at $50 \mathrm{~m} \quad$ Bering

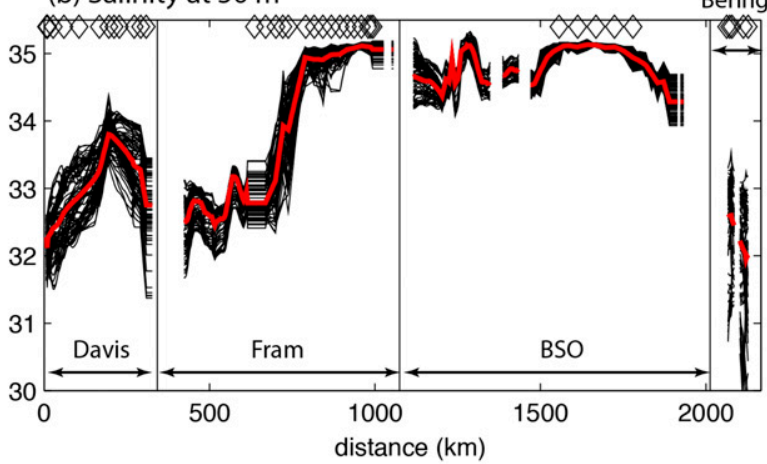

(c) Velocity $\left(\mathrm{ms}^{-1}\right)$ at $50 \mathrm{~m}$

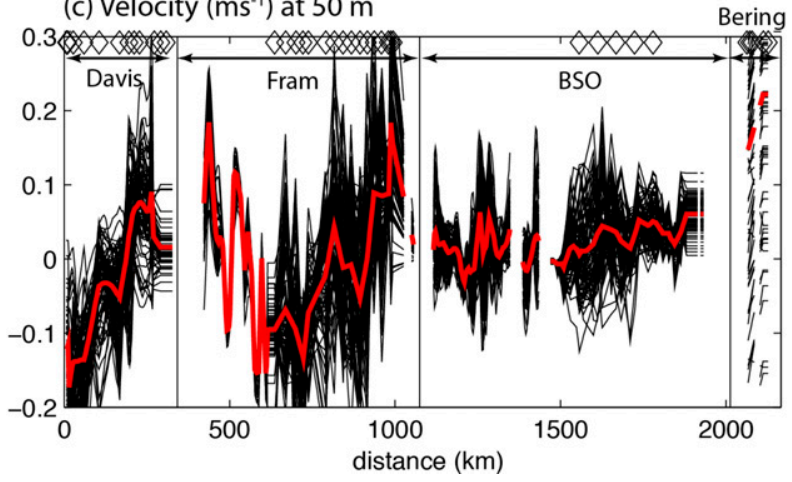

FIG. 2. (a) Constructed temperature variability at 50-m depth across the Arctic boundary. The red line shows the annual mean value and black lines show individual 5-day temperatures. Black diamonds show the location of mooring sites. (b) As in (a), but for salinity. (c) As in (a), but for velocity.

the BSO, including the Norwegian Coastal Current. The Bering Strait mean inflow $\left(0.15 \mathrm{~m} \mathrm{~s}^{-1}\right)$ has large variability superimposed $\left( \pm 0.3 \mathrm{~m} \mathrm{~s}^{-1}\right)$. It is notable that the Bering Strait exports seawater from the Arctic to the Pacific Ocean during November-December 2005 (cf. Woodgate et al. 2005).

\section{b. Initial transport imbalance and inverse model modification}

Figure 3 shows initial net volume and FW transport imbalances by month. The annual means of net (a) initial volume transport imbalance (Sv)

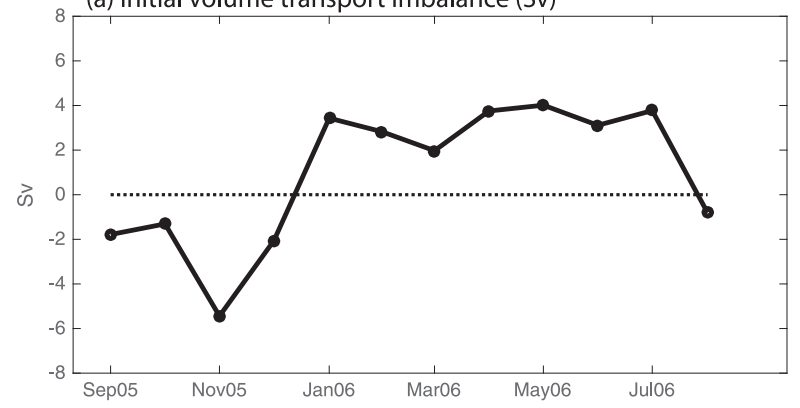

(b) initial FW transport imbalance (mSv)

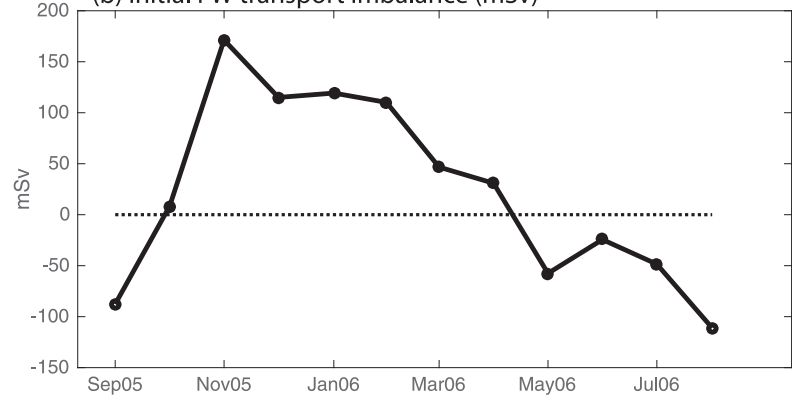

FIG. 3. Time series of monthly initial imbalances for (a) volume transport (Sv) and (b) FW transport (mSv). Zero transports of each property are shown by horizontal dotted lines.

(including surface) volume and FW transports are close to zero, at $1.0 \pm 3.1 \mathrm{~Sv}$ and $23 \pm 92 \mathrm{mSv}$, respectively. However, monthly imbalances are large. For example, November 2015 shows a volume transport deficit of $5.4 \mathrm{~Sv}$ and a FW transport surplus of $171 \mathrm{mSv}$. These imbalances are resolved by applying volume and salt constraints using the box inverse model for each month. For the inverse model modification, see appendix A for detail.

\section{c. Horizontal and diapycnal volume transports}

Figure 4 shows the spatial structure of the annualmean absolute velocity section (Fig. 4b), full-depth volume transport (Fig. 4c), and layer-specific volume transports (Fig. 4d). Their 12-monthly average and standard deviations by gateway are summarized in Table 3. Davis Strait volume transport is $-2.1 \pm 0.7 \mathrm{~Sv}$ (Table 3), comprising $-3.2 \pm 0.6 \mathrm{~Sv}$ outflow in the west (the Baffin Island Current) and 1.2 $\pm 0.8 \mathrm{~Sv}$ inflow in the east (West Greenland Current) as seen in Fig. 4c. Most of the export is found in the SURF layer, at $-1.7 \pm$ $0.4 \mathrm{~Sv}$ (Fig. $4 \mathrm{~d}$ ). In Fram Strait west of $6.5^{\circ} \mathrm{W}$, there is a cyclonic circulation of $-0.4 \pm 0.5 \mathrm{~Sv}$ over Belgica Bank. There is $-6.2 \pm 1.2 \mathrm{~Sv}$ export in the EGC between $6.5^{\circ}$ and $2.0^{\circ} \mathrm{W}$ (Table 3 ). In the WSC region east of $5.0^{\circ} \mathrm{E}$, the volume transport is $7.4 \pm 1.0 \mathrm{~Sv}$ inflow, comprising $3.7 \pm 0.5 \mathrm{~Sv} \mathrm{AW}, 1.4 \pm 0.4 \mathrm{~Sv} \mathrm{IW}$, and $2.3 \pm 0.6 \mathrm{~Sv} \mathrm{DW}$ 

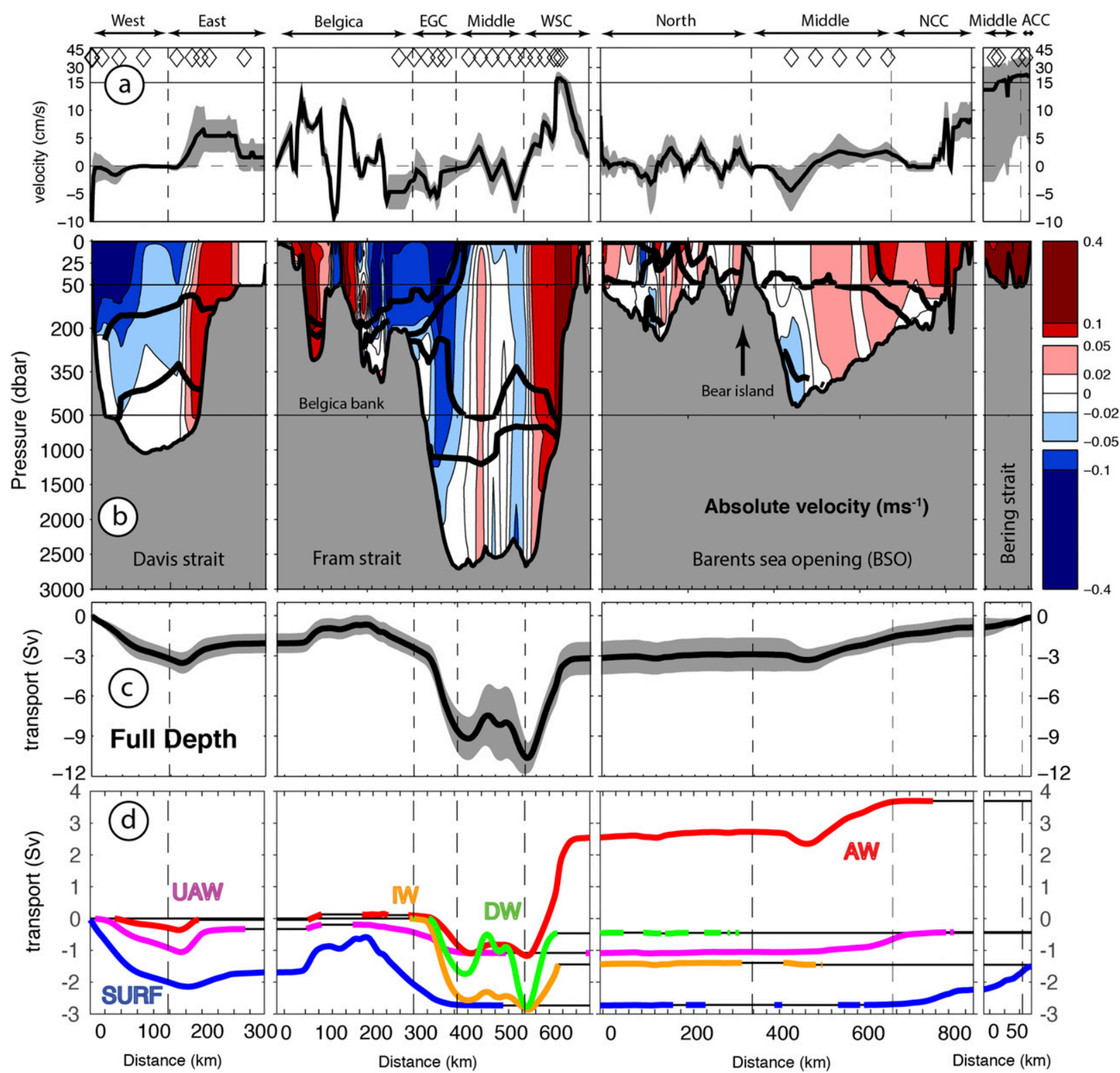

FIG. 4. (a) Inverted annual mean bottom velocities ( $\mathrm{cm} \mathrm{s}^{-1}$; black line) and its standard deviation (gray shading). Mooring locations are shown by diamonds. Note the change of vertical scale at $15 \mathrm{~cm} \mathrm{~s}^{-1}$. (b) Mass and salt conserved annual mean velocity field ( $\mathrm{m} \mathrm{s}^{-1}$ ). Thick black lines show defined water mass boundaries. Red (blue) colors show inflow to (outflow from) the Arctic. (c) Inverted annual mean fulldepth volume transport (Sv) accumulated around the boundary. The gray shade shows its standard deviation. (d) Annual mean cumulative volume transport $(\mathrm{Sv})$ for each water mass; where a specific water mass is absent from the section, the cumulative transport is plotted as a black line.

(Fig. 4d). The circulation in the DW layers is almost closed. The BSO volume transport is $2.3 \pm 1.2 \mathrm{~Sv}$ (Table 3 ) and is dominated by $1.3 \pm 1.0 \mathrm{~Sv}$, mainly AW inflow in the middle region, and by $0.7 \pm 0.2 \mathrm{~Sv}$ inflow in the Norwegian Coastal Current. The Bering Strait volume transport is $0.7 \pm 0.7 \mathrm{~Sv}$ (Table 3), found in the SURF layer (Fig. 4d).

Figure 5a summarizes the ocean volume transport time series in the four major gateways. The Davis Strait volume transport of $-2.1 \pm 0.7 \mathrm{~Sv}$ is similar to the estimate of Curry et al. (2014), $-1.7 \pm 0.5 \mathrm{~Sv}$ ( \pm uncertainty), in same period of September 2005-August 2006. Overall Fram Strait volume transport is $-1.1 \pm 1.2 \mathrm{~Sv}$, comparable to the $-2.0 \pm$ $2.7 \mathrm{~Sv}$ ( $\pm 1 \mathrm{std})$ of Schauer et al. (2008). The BSO volume transport is $2.3 \pm 1.2 \mathrm{~Sv}$, comparable to $2.0 \mathrm{~Sv}$ mainly during 1997-2007 (Smedsrud et al. 2010). Bering Strait volume transport is $0.7 \pm 0.7 \mathrm{~Sv}$, comparable to $0.8 \pm 0.2 \mathrm{~Sv}$ ( \pm uncertainty) during 1991-2004 
TABLE 3. Annual average and standard deviation of net boundary transports of volume (Sv), heat (TW), and FW (mSv) during September 2005-August 2006. Note that temperature transport (TW-eq) and FW transport (mSv-eq) are sensible to choice of reference values, while heat transport (TW) and FW transport $(\mathrm{mSv})$ are not. The heat transport (TW) and FW transport (mSv) are in bold. FW transports are calculated with reference to the area-weighted mean salinity across the section. That is $34.67 \pm 0.02$ (annual mean \pm 1 std) for the period. Ocean temperature transport and sea ice sensible heat transport are also calculated with reference to the appropriate boundary-mean potential temperature for each month. This is $1.01^{\circ} \pm 0.16^{\circ} \mathrm{C}$.

\begin{tabular}{|c|c|c|c|}
\hline & $\begin{array}{c}\text { Volume } \\
\text { transport (Sv) }\end{array}$ & $\begin{array}{l}\text { Temperature/heat transport } \\
(\mathrm{TW} \text {-eq/TW) }\end{array}$ & $\begin{array}{l}\text { FW transport } \\
(\mathrm{mSv}-\mathrm{eq} / \mathrm{mSv})\end{array}$ \\
\hline \multicolumn{4}{|l|}{ Four main gateways } \\
\hline Davis & $-2.1 \pm 0.7$ & $37 \pm 9$ & $109 \pm 13$ \\
\hline Fram & $-1.1 \pm 1.2$ & $63 \pm 17$ & $79 \pm 22$ \\
\hline $\mathrm{BSO}$ & $2.3 \pm 1.2$ & $55 \pm 28$ & $15 \pm 12$ \\
\hline Bering & $0.7 \pm 0.7$ & $-0 \pm 10$ & $-48 \pm 52$ \\
\hline \multicolumn{4}{|c|}{ Net boundary transports } \\
\hline Ocean & $-0.15 \pm 0.06$ & $154 \pm 44$ & $155 \pm 65$ \\
\hline Sea ice & $-0.06 \pm 0.04$ & $22 \pm 15$ & $48 \pm 32$ \\
\hline Ocean plus sea ice & $-0.20 \pm 0.08$ & $175 \pm 48$ & $204 \pm 85$ \\
\hline \multicolumn{4}{|c|}{ Fram Strait components } \\
\hline Belgica & $-0.4 \pm 0.5$ & $3 \pm 5$ & $11 \pm 20$ \\
\hline EGC & $-6.2 \pm 1.2$ & $23 \pm 7$ & $10 \pm 8$ \\
\hline Middle & $-2.0 \pm 1.9$ & $5 \pm 6$ & $-11 \pm 12$ \\
\hline WSC & $7.4 \pm 1.0$ & $32 \pm 9$ & $69 \pm 9$ \\
\hline
\end{tabular}

(Woodgate et al. 2005). In Bering Strait, negative transports are seen in November $(-0.5 \mathrm{~Sv})$ and December $(-0.4 \mathrm{~Sv}) 2005$, but there are often wind-forced transport reversals between October and March (Woodgate et al. 2005).

Figure $5 \mathrm{~b}$ shows sea ice volume transport estimated across the four major gateways based on PIOMAS monthly output (Zhang and Rothrock 2003). Net (mean) sea ice export of $-59 \pm 38 \mathrm{mSv}$ is dominated by Fram Strait, at $-51 \pm 34 \mathrm{mSv}$. Other contributions are small: $9 \pm 10 \mathrm{mSv}$ (Davis Strait) and $1 \pm 12 \mathrm{mSv}$ (Bering Strait). Sea ice export from the BSO is indistinguishable from zero. Our wintertime estimate (October 2005-April 2006) of $85 \mathrm{mSv}$ agrees with the 87-mSv estimate of Spreen et al. (2009) for the same period. For Davis Strait, our values agree with those of Curry et al. (2014). As far as we aware, no published sea ice import estimates are available for Bering Strait.

Table 4 summarizes the volume budgets after the inversion including residual imbalances. As prescribed in the inverse model, our full depth volume budget is closed to within $1 \mathrm{mSv}$ for each month. Net horizontal liquid ocean transports of $-0.15 \pm 0.06 \mathrm{~Sv}$ combine with sea ice exports of $-0.06 \pm 0.04 \mathrm{~Sv}$ to balance with the inverse model-derived surface $\mathrm{FW}$ input of $0.20 \pm 0.08 \mathrm{~Sv}$ (the $1-\mathrm{mSv}$ difference in totals is due to rounding error). The horizontal volume transports associated with each defined water masses are largely balanced with inverse model-derived diapycnal velocity and associated volume transports. Their shape is similar to that diagnosed in T2012, where $1.1 \pm 0.3 \mathrm{~Sv}$ upwells out of the AW layer upper surface, and $2.2 \pm 0.9 \mathrm{~Sv}$ downwells out of the AW layer lower surface. These diapycnal divergence of seawater

(a) ocean volume transports (Sv)
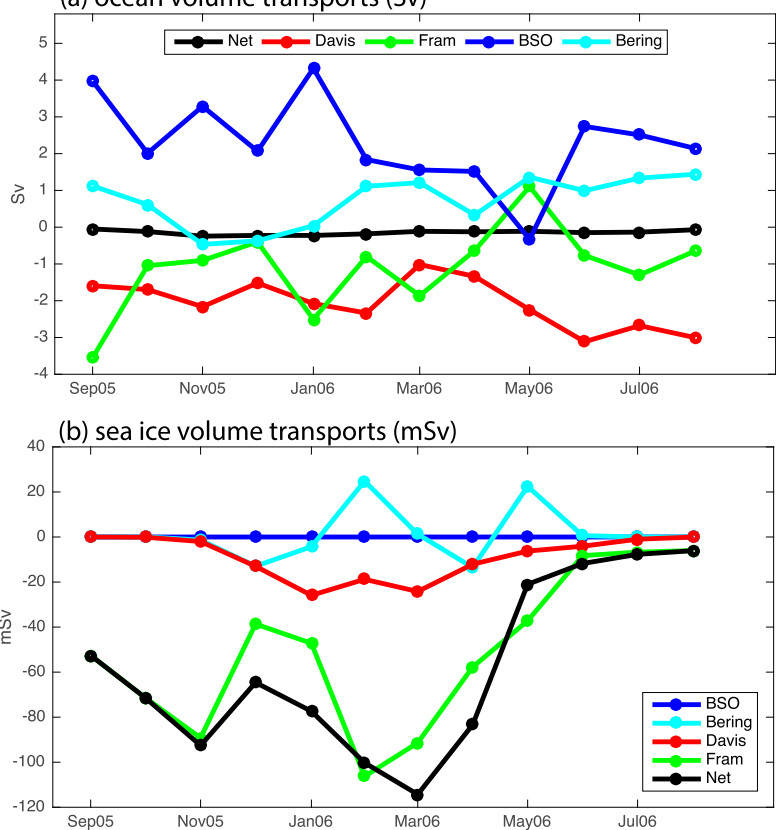

FIG. 5. (a) Ocean volume transport (Sv) time series in the Arctic four main gateways; shown are net transport (black) and individual gateway transports (colors). (b) As in (a), but for sea ice volume transport time series $(\mathrm{mSv})$. 
TABLE 4. Volume budget (Sv) after the inversion for the five defined layer groups and full depth. The mean and standard deviation are shown, which is based on estimates for 12 months. The positive (negative) values show convergence (divergence) of seawater due to horizontal transport, diapycnal transport, and surface FW flux plus sea ice in second to fourth columns. In the fifth column, positive (negative) values show a surplus (deficit) in residual imbalances. Note that the diapycnal transport convergence for full depth is zero from the definition, and surface FW flux plus sea ice convergences in UAW, AW, IW, and DW are zero from the box inverse model setting. They are indicated by - .

\begin{tabular}{lcccc}
\hline \hline & Horizontal transport & Diapycnal transport & Surface FW flux plus sea ice & Residual imbalances \\
\hline SURF & $-1.51 \pm 1.04$ & $+0.17 \pm 0.34$ & $+0.15 \pm 0.06$ & $-1.19 \pm 1.01$ \\
UAW & $-0.43 \pm 0.44$ & $+0.83 \pm 0.40$ & - & $+0.40 \pm 0.33$ \\
AW & $+3.70 \pm 1.10$ & $-3.20 \pm 1.02$ & - & $+0.49 \pm 0.42$ \\
IW & $-1.45 \pm 0.49$ & $+1.70 \pm 0.39$ & - & $+0.24 \pm 0.22$ \\
DW & $-0.45 \pm 0.82$ & $+0.51 \pm 0.78$ & $+0.15 \pm 0.06$ & $+0.06 \pm 0.05$ \\
Full depth & $-0.15 \pm 0.06$ & - & $0.00 \pm 0.00$ \\
\hline
\end{tabular}

in AW layer at rate of $-3.2 \pm 1.0 \mathrm{~Sv}$ is mostly balanced with the horizontal convergence of seawater at rate of $3.7 \pm$ $1.1 \mathrm{~Sv}$.

Although the derived diapycnal transport is consistent with T2012, the quantified diapycnal transports needs to be treated with caution. They are derived from point measurements of velocity by mooring instruments (five sampling depths in Fram Strait at most) with the linear interpolation method we use to generate the gridded fields. These uncertainties are reflected into the a priori uncertainties in the box inverse model setting (Table A1). Consequently, there are some residual imbalances in each defined model layers after the inversion, such as $+0.49 \pm 0.33$ in $\mathrm{AW}$ and $-1.19 \pm$ $1.01 \mathrm{~Sv}$ in the SURF layer. These imbalances are within the a priori uncertainties.

\section{d. Temperature and heat transports}

Key to the visualization of the ocean temperature transports is the product $\theta^{\prime} v^{\prime}$, shown in Fig. 6a, with associated full-depth and layer transports. The greatest contributions of $\theta^{\prime} v^{\prime}$ to the net heat transport appear in the upper $\sim 200 \mathrm{~m}$ in western Davis Strait, over Belgica Bank and in the EGC, and the central BSO and Norwegian Coastal Current regions; and to greater depths, $\sim 500 \mathrm{~m}$, in the WSC. Integrated around the boundary, the liquid ocean component of the heat flux is $154 \pm 44 \mathrm{TW}$ (annual mean $\pm 1 \mathrm{std}$ ) as seen in Fig. 6b. The dominant contribution arises from the AW $(69 \pm 18$ TW-eq), followed by the SURF ( $47 \pm 21 \mathrm{TW}$-eq) and the UAW (30 $\pm 10 \mathrm{TW}$-eq) as shown in Table 5.

Figure 7 a shows the time series of monthly ocean heat transports and the contribution of each gateway to the total. There is a clear seasonal cycle in the heat transport, with the highest values $(\sim 200 \mathrm{TW})$ in September-January and the lowest values $(\sim 120 \mathrm{TW})$ in March-June. This variability mainly stems from the BSO and the Fram Strait. Figure $7 \mathrm{~b}$ shows the net heat flux across the boundary as a combination of ocean heat transport and sea ice latent plus sensible heat transports. The annual mean ( $\pm 1 \mathrm{std})$ heat flux is $175 \pm 48 \mathrm{TW}$. The amplitude and phase of the seasonal cycle are slightly modified by the addition of the sea ice component.

We next examine the contributions to seasonal variability in ocean heat transport by isolating the time-mean and time-varying contributions of temperature and velocity to total heat transport, following Lique et al. (2009). For each of 12 months $k(k=1, \ldots, 12)$, the ocean heat transport $\left[F_{H, k}^{o}\left(\theta^{\prime}, v^{\prime}\right)=\rho_{o} c_{p}^{o} \iint\left(\theta^{\prime}, v^{\prime}\right) d x d z\right]$ is decomposed into a time-mean component and three time-varying components as

$$
\begin{aligned}
F_{H, k}^{o}\left(\theta^{\prime}, \boldsymbol{v}^{\prime}\right)= & \rho c_{p} \iint\left[\left(\left\langle\theta^{\prime}\right\rangle+\theta^{\dagger}\right)\left(\left\langle v^{\prime}\right\rangle+v^{\dagger}\right)\right] d x d z \\
= & F_{H, k}^{o}\left(\left\langle\theta^{\prime}\right\rangle,\left\langle v^{\prime}\right\rangle\right)+F_{H, k}^{o}\left(\left\langle\theta^{\prime}\right\rangle, v^{\dagger}\right) \\
& +F_{H, k}^{o}\left(\theta^{\dagger},\left\langle v^{\prime}\right\rangle\right)+F_{H, k}^{o}\left(\theta^{\dagger}, v^{\dagger}\right),
\end{aligned}
$$

where angle brackets indicate time averaged fields over the 12 months, and the dagger indicates the deviation from these averaged fields for each month. The term $F_{H, k}^{o}\left(\left\langle\theta^{\prime}\right\rangle,\left\langle v^{\prime}\right\rangle\right)$ is the "mean transport" calculated as the integral of the product of the annualmean velocity and temperature fields. The term $F_{H, k}^{o}\left(\left\langle\theta^{\prime}\right\rangle, v^{\dagger}\right)$ is the "velocity-driven" component resulting from monthly changes in advection of the annualmean temperature field, and similarly $F_{H, k}^{o}\left(\theta^{\dagger},\left\langle v^{\prime}\right\rangle\right)$ is the "temperature-driven" component resulting from monthly changes of temperature advected by the annualmean velocity field. Finally, $F_{H, k}^{o}\left(\theta^{\dagger}, v^{\dagger}\right)$ is the "correlation term" of monthly potential temperature and velocity anomalies.

Figure $7 \mathrm{c}$ shows all of the four components on the RHS of (3). Mean transport $F_{H, k}^{o}\left(\left\langle\theta^{\prime}\right\rangle,\left\langle v^{\prime}\right\rangle\right)=148 \pm 1 \mathrm{TW}$; the absolute value is similar to the inverse model annualmean heat transport of $154 \pm 44 \mathrm{TW}$. Velocity-driven $F_{H, k}^{o}\left(\left\langle\theta^{\prime}\right\rangle, v^{\dagger}\right)=2 \pm 28 \mathrm{TW}$ and temperature-driven 


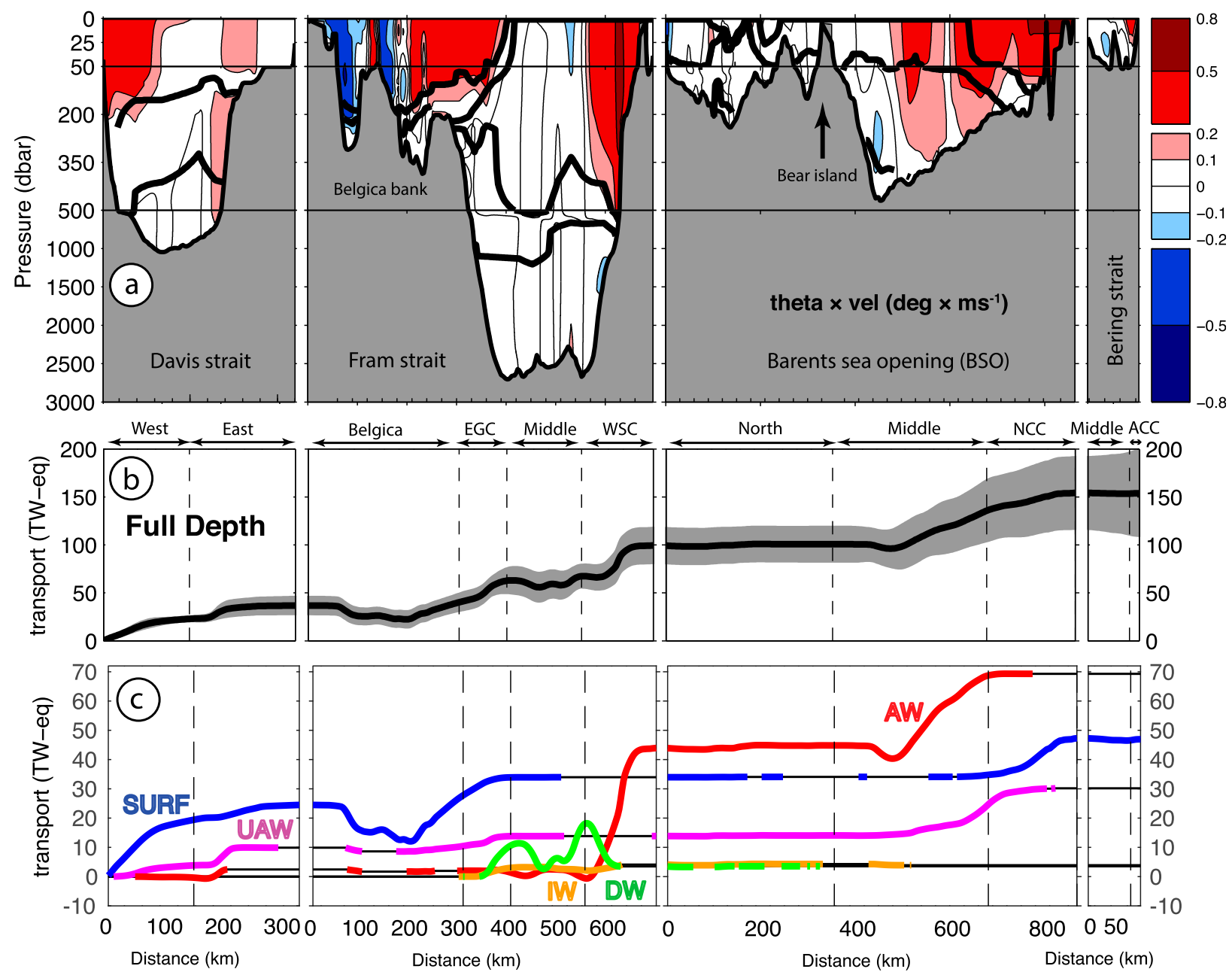

FIG. 6. (a) Annual mean temperature flux $\left({ }^{\circ} \mathrm{C} \mathrm{m} \mathrm{s}^{-1}\right)$ section calculated from the potential temperature anomaly section and final velocity field $\left(\theta^{\prime} v^{\prime}\right)$; thick black lines show defined water mass boundaries, and positive values show temperature entering the Arctic. (b) Annual mean cumulative full depth temperature transport (TW-eq) around the section (black line) and its standard deviation (gray shading). (c) Annual mean cumulative temperature transport (TW-eq) of defined water masses; where a specific water mass is absent from the section, the accumulated transport is plotted as a black line.

$F_{H, k}^{o}\left(\theta^{\dagger},\left\langle\boldsymbol{v}^{\prime}\right\rangle\right)=-2 \pm 25 \mathrm{TW}$ make contributions of ilar magnitude to the seasonal variability in net heat transport. However, the shapes of their variability are different. While velocity-driven $F_{H, k}^{o}\left(\left\langle\theta^{\prime}\right\rangle, v^{\dagger}\right)$ has month-to-month transport variability, temperature-driven $F_{H, k}^{o}\left(\left\langle\theta^{\prime}\right\rangle, v^{\dagger}\right)$ has a smooth seasonal cycle. The correlation term $F_{H, k}^{o}\left(\theta^{\dagger}, v^{\dagger}\right)=7 \pm 4 \mathrm{TW}$ makes only a minor contribution to the seasonal cycle variability. We next examine these components in different water masses. Table 5 shows that velocity-driven month-to-month variability $( \pm 28 \mathrm{TW})$ stems from the AW layer $( \pm 17 \mathrm{TW}$-eq) and that the temperature-driven smooth seasonal cycle $( \pm 25 \mathrm{TW})$ stems from the SURF layer (17 TW-eq). This temperature variability arises from inflow regions around the boundary: the eastern part of Davis Strait, the WSC region in Fram Strait, the BSO, and Bering Strait, seen in Fig. 2a.

We next recalculate our temperature transports in each gateway to compare with previous estimates (annual mean \pm $1 \mathrm{std}$ ). In the BSO, we find $64 \pm 33 \mathrm{TW}$-eq referenced to $0.0^{\circ} \mathrm{C}$, consistent with the estimate of $73 \mathrm{TW}$-eq referenced to $0.0^{\circ} \mathrm{C}$ (Smedsrud et al. 2010). Davis Strait temperature transport referenced to $-0.1^{\circ} \mathrm{C}$ is $29 \pm 10 \mathrm{TW}$-eq, comparable to the annual mean estimate of $20 \pm 9$ TW-eq ( \pm uncertainty) during 2004-05 (Curry et al. 2011). Bering Strait temperature transport referenced to $-1.9^{\circ} \mathrm{C}$ is $8 \pm 13$ TW-eq. This is smaller than the most recent estimate of about 23 TW-eq, which includes a correction of 3 TW-eq for the Alaskan Coastal Current, during August and October 2005 , referenced to $-1.9^{\circ} \mathrm{C}$ (Woodgate et al. 2010). 
TABLE 5. Full depth ocean heat transport (TW) and its composition of temperature transport (TW-eq) in each water mass. The velocity-driven and temperature-driven components of these quantities are shown in the third and fourth columns. The mean and standard deviation is based on estimates for 12 months. For each water mass, only standard deviations are shown because mean values are always close to zero. The full depth heat transports, which are insensitive to choice of reference temperature, are in bold.

\begin{tabular}{lccc}
\hline \hline & $\begin{array}{c}\text { Total } \\
\text { variability }\end{array}$ & $\begin{array}{c}\text { Velocity } \\
\text { driven }\end{array}$ & $\begin{array}{c}\text { Temperature } \\
\text { driven }\end{array}$ \\
\hline SURF & $47 \pm 21$ & \pm 6 & \pm 17 \\
UAW & $30 \pm 10$ & \pm 6 & \pm 4 \\
AW & $69 \pm 18$ & \pm 17 & \pm 5 \\
IW & $4 \pm 3$ & \pm 1 & \pm 2 \\
DW & $4 \pm 6$ & \pm 6 & \pm 2 \\
Full depth & $\mathbf{1 5 4} \pm \mathbf{4 4}$ & $\mathbf{2} \pm \mathbf{2 8}$ & $\mathbf{- 2} \pm \mathbf{2 5}$ \\
\hline
\end{tabular}

The WSC temperature transport referenced to $-0.1^{\circ} \mathrm{C}$ is $58 \pm 10 \mathrm{TW}$-eq. This is larger than the recent annual mean temperature transport estimate of 28-44 TW-eq referenced to $-0.1^{\circ} \mathrm{C}$ based on mooring observations during 1997-2000 (Schauer et al. 2004). Last, Schauer and Beszczynska-Möller (2009) estimate decadal heat transports associated with AW inflow in Fram Strait since 1998 employing their "tube" method. They estimate heat transports of 40-50 TW during 2003-07. We find heat transport associated with AW inflow in Fram Strait accounts for $26 \%-32 \%$ of the $154 \pm 44 \mathrm{TW}$ total ocean heat transport.

\section{e. FW transports}

FW transports are visualized using $S^{\prime} v^{\prime}$, as for temperature transport, and the product is shown in Fig. 8 with associated full-depth and layer transports. The derived FW flux is dominated by the upper $\sim 200 \mathrm{~m}$, with large contributions in Davis Strait, Belgica Bank, the EGC, and Bering Strait, and contributions from greater depths $(\sim 500 \mathrm{~m})$ in the WSC. FW transport mirrors temperature transport to a large extent. The annual mean ocean FW transport ( \pm 1 std) is $155 \pm$ $65 \mathrm{mSv}$, with major contributions from the SURF $(79 \pm 59 \mathrm{mSv}$-eq) and $\mathrm{AW}$ layers $(57 \pm 15 \mathrm{mSv}$-eq $)$ as shown in Table 6 .

Figure 9a shows the time series of net ocean FW transport and the contribution of each gateway to the total. There is a clear seasonal cycle, with higher values $\sim 250 \mathrm{mSv}$ in November-January and lower values of $\sim 80 \mathrm{mSv}$ in August-September. Only the BSO contribution to the total is small; the transports in Davis Strait $(109 \pm 13 \mathrm{mSv}$-eq) and Fram Strait $(79 \pm 22 \mathrm{mSv}$-eq) are of similar magnitude; but the variability is clearly dominated by Bering Strait ( $-48 \pm 52 \mathrm{mSv}-\mathrm{eq})$. Figure $9 \mathrm{~b}$ shows the boundary FW flux time series as the sum of ocean and sea ice FW transports. The annual mean
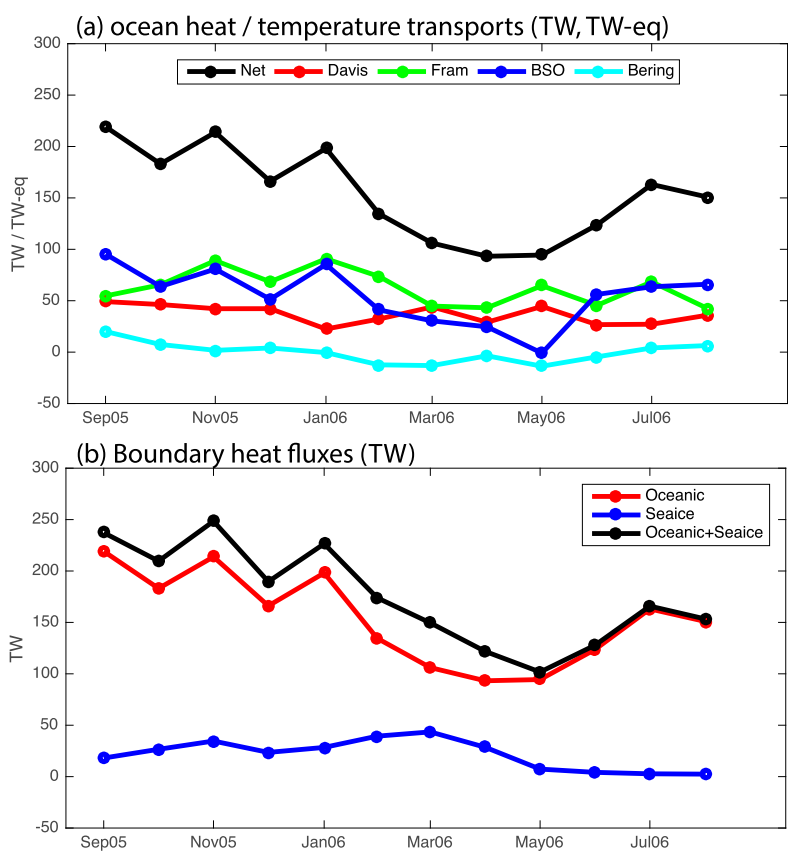

(c) Decomposition of net ocean heat transports (TW)

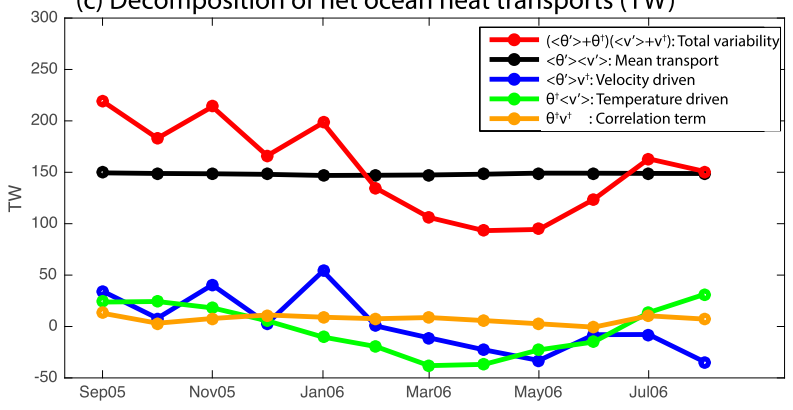

FIG. 7. (a) Ocean heat transport (TW) and temperature transport (TW-eq) time series; shown are net heat transport (black) and each gateway temperature transports (colors). (b) Boundary heat flux (TW) time series (black); with the ocean (red) and sea ice (blue) contributions indicated. (c) Decomposition of net ocean heat transports (TW) into different components. See detail of the decomposition in main text.

( $\pm 1 \mathrm{std})$ is $204 \pm 85 \mathrm{mSv}$, with the ocean seasonal cycle modified by the smaller signal from the sea ice FW transport. Higher values of $\sim 300 \mathrm{mSv}$ are seen in NovemberJanuary, and lower values of $\sim 130 \mathrm{mSv}$ in May-September.

We next pursue the same decomposition for monthly FW transports $\left(F_{\mathrm{FW}, k}^{o}\right)$ as for ocean heat transports in (3) above:

$$
\begin{aligned}
F_{\mathrm{FW}, k}^{o}\left(S^{\prime}, v^{\prime}\right)= & F_{\mathrm{FW}, k}^{o}\left(\left\langle S^{\prime}\right\rangle,\left\langle\boldsymbol{v}^{\prime}\right\rangle\right)+F_{\mathrm{FW}, k}^{o}\left(\left\langle S^{\prime}\right\rangle, \boldsymbol{v}^{\dagger}\right) \\
& +F_{\mathrm{FW}, k}^{o}\left(S^{\dagger},\left\langle\boldsymbol{v}^{\prime}\right\rangle\right)+F_{\mathrm{FW}, k}^{o}\left(S^{\dagger}, v^{\dagger}\right) .
\end{aligned}
$$

We refer to $F_{\mathrm{FW}, k}^{o}\left(\left\langle S^{\prime}\right\rangle,\left\langle v^{\prime}\right\rangle\right)$ as the mean transport component, $F_{\mathrm{FW}, k}^{o}\left(\left\langle S^{\prime}\right\rangle, \boldsymbol{v}^{\dagger}\right)$ as the velocity-driven component, $F_{\mathrm{FW}, k}^{o}\left(S^{\dagger},\left\langle v^{\prime}\right\rangle\right)$ as the salinity-driven component, and $F_{\mathrm{FW}, k}^{o}\left(S^{\dagger}, v^{\dagger}\right)$ as the correlation term. 

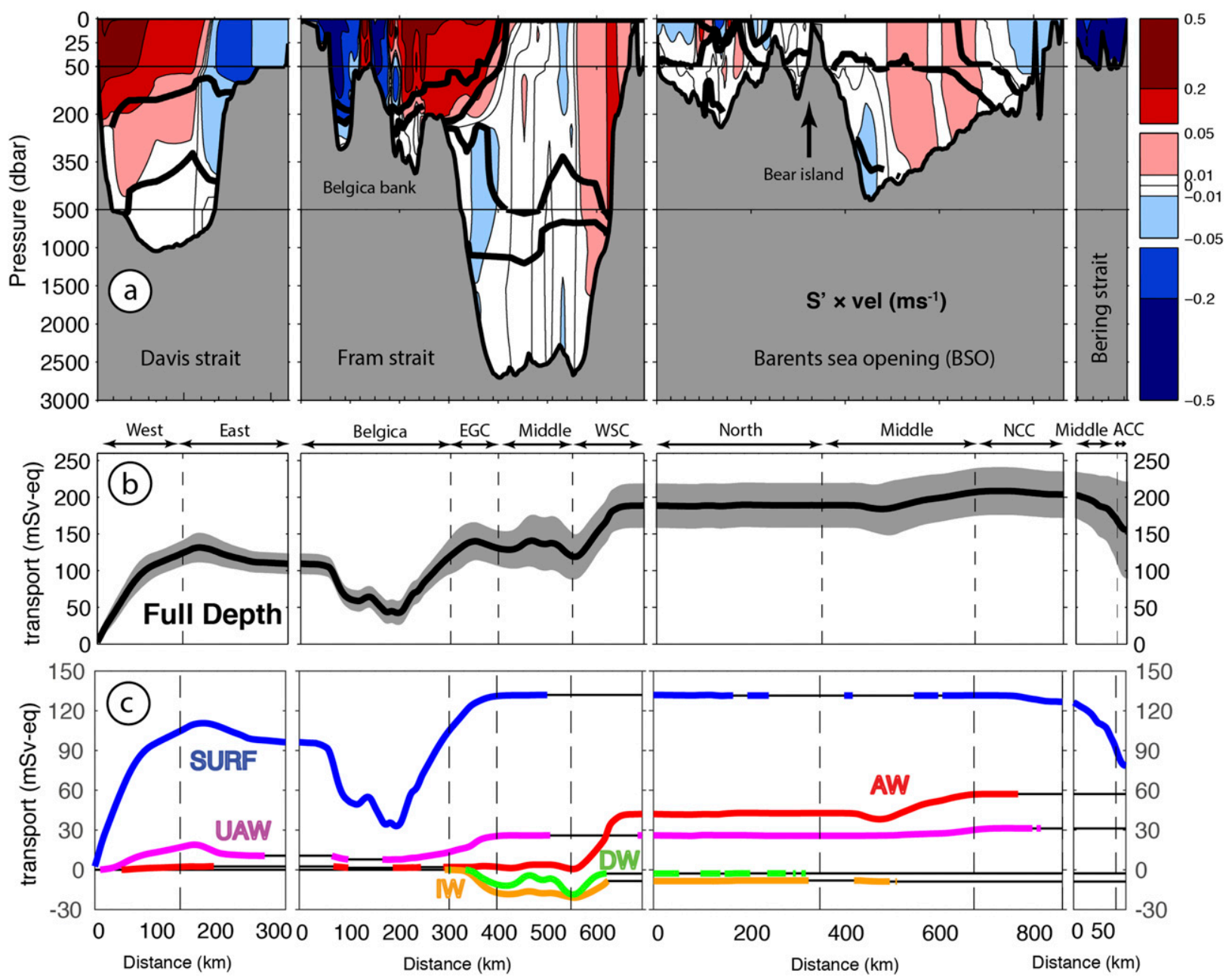

FIG. 8. (a) Annual mean FW flux section $\left(\mathrm{m} \mathrm{s}^{-1}\right)$ calculated from the salinity anomaly and final velocity fields $\left(S^{\prime} v^{\prime}\right)$; thick black lines show defined water mass boundaries. (b) Annual mean cumulative full depth FW transport (mSv-eq) around the section in black and its standard deviation in gray shading. (c) Annual mean cumulative FW transport (mSv-eq) of the defined water masses. Where a specific water mass is absent from the section, the accumulated transport is plotted as a black line.

Figure 9c shows all of the four components on the RHS of (4). Again, the correlation term $F_{\mathrm{FW}, k}^{o}\left(S^{\dagger}, v^{\dagger}\right)$ is small but, in contrast to heat transports, it is clear that ocean FW transport variability is dominated by the velocity-driven component $F_{\mathrm{FW}, k}^{o}\left(\left\langle S^{\prime}\right\rangle, v^{\dagger}\right)$. The contribution of the salinity-driven component $F_{\mathrm{FW}, k}^{o}\left(S^{\dagger},\left\langle v^{\prime}\right\rangle\right)$ is minor because the phase of the salinity variability is very similar in both inflow and outflow regions, so that the contribution of salinity variability in each gateway cancels out. We next examine these components in different water masses. Table 6 shows that the FW transport variability is concentrated just in the SURF layer, driven by velocity variability. This velocity variability mainly stems from the Bering Strait (Fig. 9a).

We next recalculate our results with different salinity reference values for comparison with previous studies (annual mean \pm 1 std). Our Davis Strait FW transport is $117 \pm 14 \mathrm{mSv}$-eq, referenced to 34.8. Curry et al. (2014) estimates $97 \pm 15 \mathrm{mSv}$-eq ( \pm uncertainty) for the same period and the same reference value. In Fram Strait, de Steur et al. (2009) estimates the annual mean liquid FW outflow in the EGC region $\left(6.5-0.0^{\circ} \mathrm{W}\right)$, referenced to 34.9 , as $40.4 \pm 14.4 \mathrm{mSv}$-eq ( $\pm 1 \mathrm{std}$ ) based on 1998-2008 mooring observations. This value is similar to our liquid FW flux of $52 \pm 11 \mathrm{mSv}$-eq, for $6.5^{\circ}-2.0^{\circ} \mathrm{W}$ and the same reference salinity. The BSO FW flux referenced to 35.0 is $-8 \pm 5 \mathrm{mSv}$-eq, compared to $-17 \mathrm{mSv}$-eq by Smedsrud et al. (2010), who use mooring observations and a reference salinity of 35.0. The Bering Strait FW transport is $51 \pm 54 \mathrm{mSv}$-eq referenced to 34.8 , which is smaller than the $80 \pm 10 \mathrm{mSv}$-eq ( \pm uncertainty) estimate of Woodgate and Aagaard (2005), based on 1991-2004 mooring 
TABLE 6. As in Table 5, but for FW transports (mSv, mSv-eq). The FW transports $(\mathrm{mSv})$, which are insensitive to choice of reference salinity, are in bold.

\begin{tabular}{lccc}
\hline \hline & $\begin{array}{c}\text { Total } \\
\text { variability }\end{array}$ & $\begin{array}{c}\text { Velocity } \\
\text { driven }\end{array}$ & $\begin{array}{c}\text { Salinity } \\
\text { driven }\end{array}$ \\
\hline SURF & $79 \pm 59$ & \pm 56 & \pm 22 \\
UAW & $31 \pm 9$ & \pm 7 & \pm 6 \\
AW & $57 \pm 15$ & \pm 14 & \pm 3 \\
IW & $-9 \pm 5$ & \pm 3 & \pm 3 \\
DW & $-3 \pm 5$ & \pm 5 & \pm 2 \\
Full depth & $\mathbf{1 5 5} \pm \mathbf{6 5}$ & $\mathbf{8} \pm \mathbf{5 9}$ & $\mathbf{0} \pm \mathbf{2 0}$ \\
\hline
\end{tabular}

observations. They include contributions from the Alaskan Coastal Current and salinity stratification, equivalent to $13 \mathrm{mSv}$-eq each. Although we include Alaskan Coastal Current and salinity stratification based on NEMO output, the sum of these contributions is small, $5 \pm 9 \mathrm{mSv}$-eq. This and the southward FW transport in November-December 2005 (Fig. 9a) may explain the discrepancies.

\section{f. Uncertainty of the total ocean heat and FW transports}

We have one important point of comparison for our new, mooring-based flux results: the calculations of T2012. They are derived from hydrographic CTD measurements taken over 32 days from 9 August to 10 September 2005, and bottom mooring measurement within 2 months from 21 July to 27 September for the reference velocity (see T2012's Fig. 3). Therefore, we are aware that the overlap between our new results and those of T2012 is imperfect. See details of a comparison between first month mooring based estimate in September 2005 and T2012 for online supplemental information section B. Note that we also update the T2012 estimate including International Bathymetric Chart of the Arctic Ocean (IBCAO) bathymetry, updating the inverse model setting and correcting transport weighted seawater properties. Details are provided in online supplemental information section $\mathrm{C}$.

Next, we examine the robustness of the total ocean heat and FW transports by investigating (first) the impact of the NEMO model output, where it is used to fill unobserved regions (the upper $50 \mathrm{~m}$, and over the shallow shelves), and (second) the sparseness of the salinity measurements in Fram Strait. In short, we find that unobserved variability in the upper $50 \mathrm{~m}$ and over shelf regions affects the net ocean heat transport by less than $7 \mathrm{TW}$ ( $5 \%$ of the total ocean heat transport; Fig. 10a). For the ocean FW transport uncertainties, they stem mainly from the unobserved variability in the upper $50 \mathrm{~m}$ in western Davis Strait, Belgica
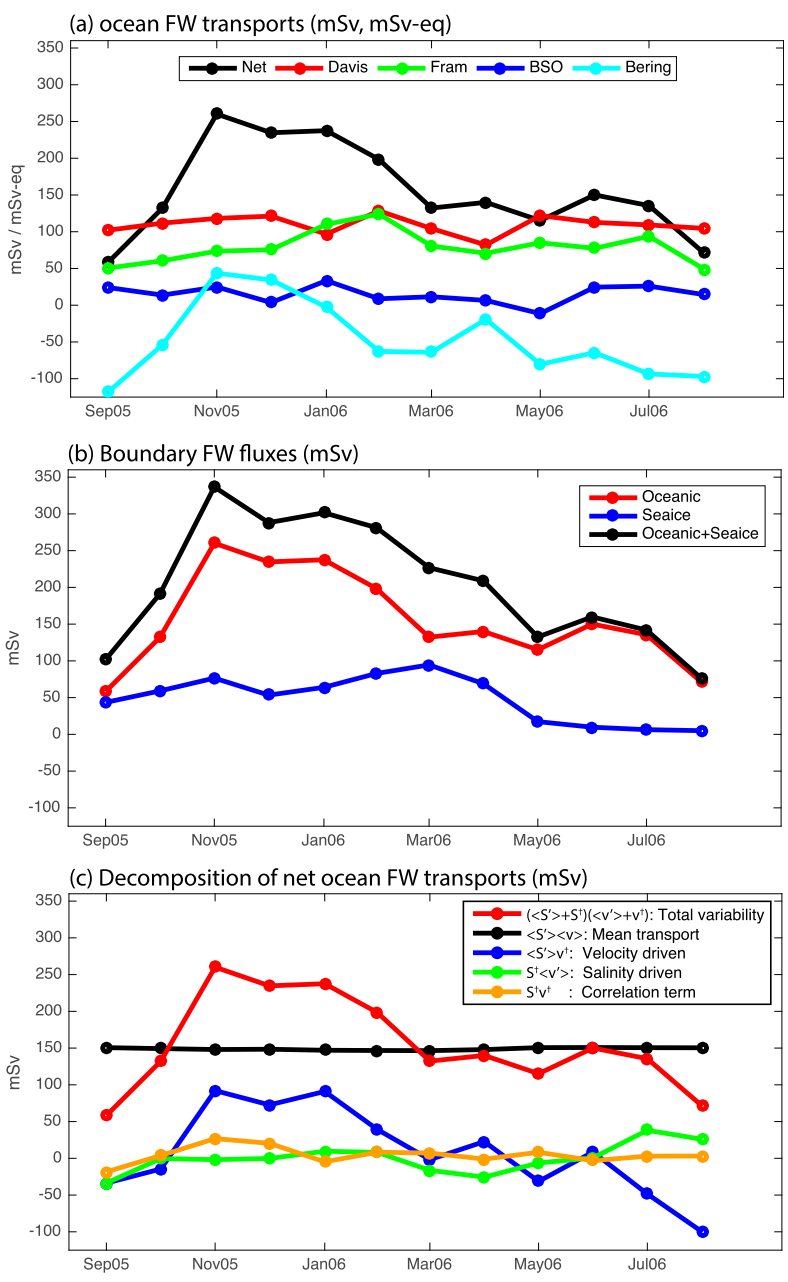

FIG. 9. (a) Ocean FW transport time series: shown are net transport (mSv; black) and each gateway transports (mSv-eq; colors). (b) Boundary FW flux (mSv) time series (black); with the ocean (red) and sea ice (blue) contributions indicated. (c) Decomposition of net ocean FW transports ( $\mathrm{mSv}$ ) into different components. See details of the decomposition in the main text.

Bank variability in Fram Strait, and sparse salinity measurements in the EGC region in Fram Strait (Figs. 10b-e). We estimate that their uncertainties are each $\sim 30 \mathrm{mSv}$-eq (19\% of the total ocean FW transport). Improved observations in these regions would reduce uncertainty in FW transport estimates. See appendix B for more detail.

\section{g. Transport-weighted mean properties and water mass transformation}

Water mass transformations can be interpreted as a result of air-sea heat and FW fluxes in outcrop regions at the sea surface and interior mixing (Walin 1982). In the Arctic Ocean, Pemberton et al. (2015) investigate the causes of 

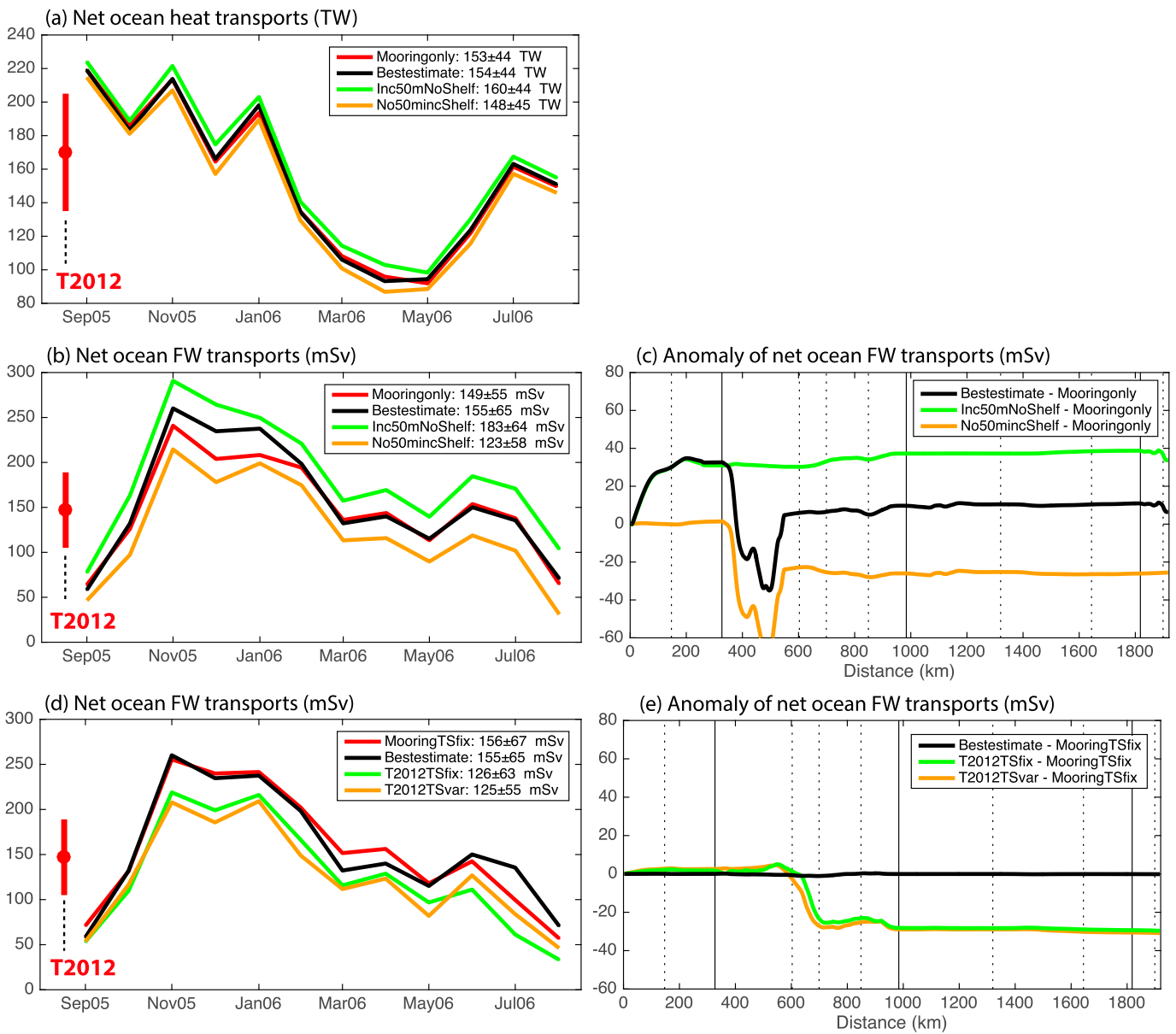

FIG. 10. (a) Net ocean heat transports (TW) with different sets of temperature, salinity, and velocity sections to quantify an impact of upper $50 \mathrm{~m}$ and shelf region variability on the transport estimate. For the definition of different set of estimates in different colors, see appendix B for details. T2012's net ocean heat transport estimate and its uncertainty estimate are shown at the beginning of the time series as a red dot and a vertical bar, respectively. (b) As in (a), but for net ocean FW transport (mSv). (c) Annual mean cumulative ocean FW transports anomaly $(\mathrm{mSv})$ across the Arctic boundary reference to mooring only transport estimate, based on four different FW transport estimates in (b). (d) As in (b), but for quantifying an impact of sparse salinity measurements in Fram Strait on the FW transport estimate (mSv). (e) As in (c), but based on four different FW transport estimates in (d).

water mass transformation in $\theta-S$ coordinates based on cores $\left(1^{\circ}\right)$ NEMO model output. Therefore, it is useful to translate our boundary heat and FW flux time series into water mass transformations in $\theta-S$ coordinates to provide observation-based reference values for future studies.

As in T2012, monthly velocity fields are transformed from geographical coordinates (distance against pressure) into $\theta-S$ coordinates, gridded with $\Delta \theta=0.2^{\circ} \mathrm{C}$ and $\Delta S=0.05$. All transports within each $\theta-S$ grid box are summed and the net transports in the class are calculated. Based on the net volume transports $\left(\mathrm{m}^{3} \mathrm{~s}^{-1}\right)$ per class, volume transport and seawater property change associated with the water mass transformation are calculated. These quantities are related to surface heat and FW fluxes as

$$
\begin{aligned}
& F_{H}^{\text {surf }}=-\rho_{o} c_{p}^{o}\left(\Theta_{\text {in }}-\Theta_{\text {out }}^{o i}\right) V_{\text {in }}+F_{H}^{\text {stor }}, \text { and } \\
& F_{\text {vol }}^{\text {surf }}=\frac{1}{S_{\text {out }}^{o i}}\left(S_{\text {in }}-S_{\text {out }}^{o i}\right) V_{\text {in }}+F_{\mathrm{FW}}^{\text {stor }},
\end{aligned}
$$

where $V_{\text {in }}$ is inflow volume transport associated with the water mass transformation, $\Theta_{\text {in }}$ and $S_{\text {in }}$ are transportweighted inflow potential temperature and salinity, and $\Theta_{\text {out }}^{o i}$ and $S_{\text {out }}^{o i}$ are transport-weighted outflow potential temperature and salinity including the sea ice contributions. These are alternative forms of (1) and (2); see appendix $\mathrm{C}$ for derivation. 
(a) Volume transport (Sv)

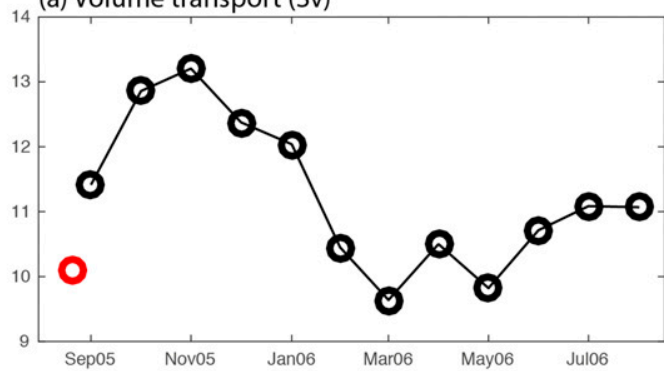

(b) Potential temperature $\left({ }^{\circ} \mathrm{C}\right)$

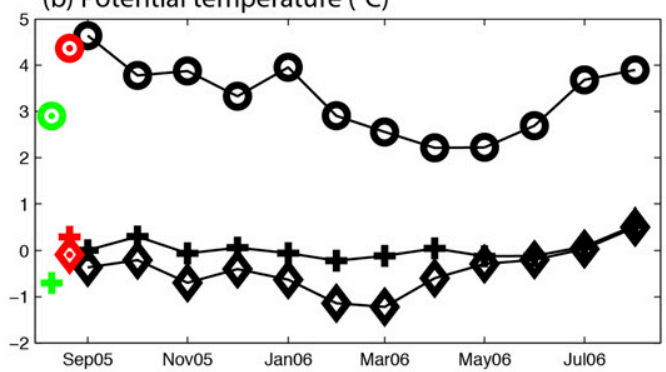

(c) Salinity

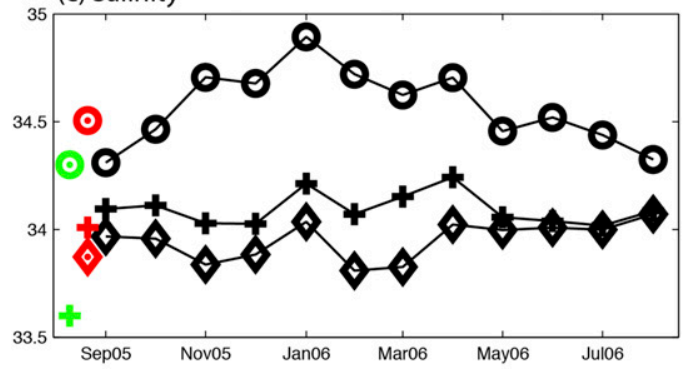

(d) Potential density $\left(\mathrm{kg} \mathrm{m}^{-3}\right)$

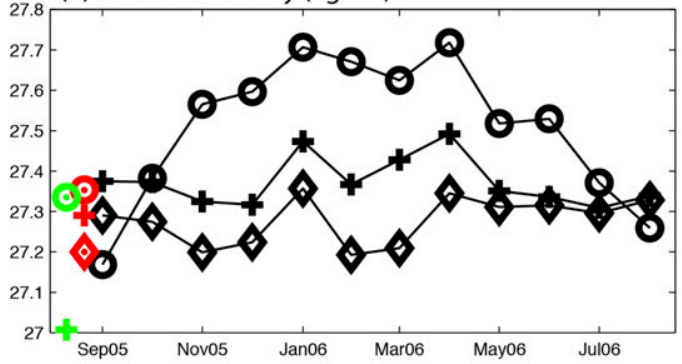

(e) Boundary heat flux (TW)

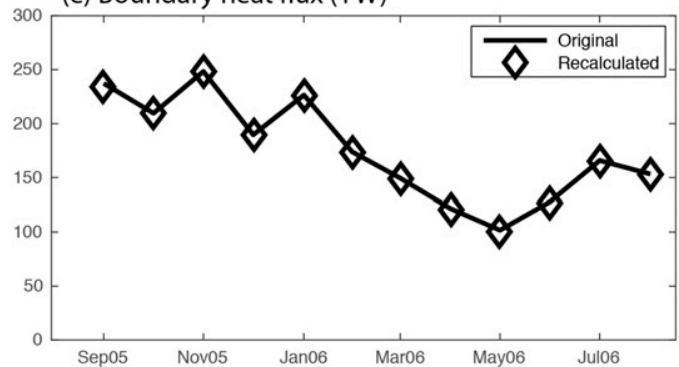

(f) Boundary FW flux (mSv)

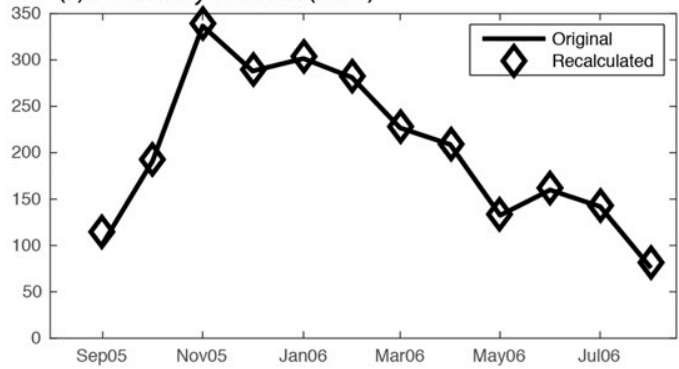

FIG. 11. (a) Volume transport (Sv) in inflow (i.e., sum of water going into the Arctic), associated with the water mass transformation. The updated T2012 estimates are shown at beginning of the time series as a red circle. (b) Monthly volume transport weighted potential temperature $\left({ }^{\circ} \mathrm{C}\right)$ in inflow (circle) and outflow without sea ice (cross), and with sea ice (diamond). T2012's estimates and Pemberton et al.'s (2015) estimates are shown at beginning of the time series by red and green symbols, respectively. (c) As in (b), but for salinity. (d) As in (b), but for potential density $\left(\mathrm{kg} \mathrm{m}^{-3}\right)$. (e) Original boundary heat flux time series (TW; Fig. 7b) is shown by a solid line and boundary heat flux (TW) based on (5) is shown by diamonds. (f) Original boundary FW flux (mSv; Fig. 9b) is shown by a solid line and boundary FW flux (mSv) based on (6) is shown by diamonds.

Figure 11a shows the time series of $V_{\text {in }}$, with annual mean $( \pm 1 \mathrm{std}) 11.3 \pm 1.2 \mathrm{~Sv}$, and with a small seasonal cycle of $\sim 1 \mathrm{~Sv}$, higher during September-January and lower during February-May. Figure 11b shows the time series of $\Theta_{\text {in }}$, transport-weighted outflow potential temperature without sea ice contribution $\left(\Theta_{\text {out }}^{o}\right)$, and $\Theta_{\text {out }}^{o i}$. Their annual means $( \pm 1 \mathrm{std})$ are $3.31^{\circ} \pm 0.78^{\circ} \mathrm{C}, 0.03 \pm$ $0.21^{\circ} \mathrm{C}$, and $-0.43^{\circ} \pm 0.48^{\circ} \mathrm{C}$, respectively. Note that $\Theta_{\text {in }}$ is highest in late summer and lowest in late winter; $\Theta_{\text {out }}^{o}$ has much lower temporal variability than $\Theta_{\text {in }} ; \Theta_{\text {out }}^{o}$ remains close to $0^{\circ} \mathrm{C}$. Adding the sea ice contribution introduces a modest seasonal cycle, so that $\Theta_{\text {out }}^{o i}$ has lower values than $\Theta_{\text {out }}^{o}$ between autumn and late winter, by $0.3^{\circ}-0.7^{\circ} \mathrm{C}$.

Figure $11 \mathrm{c}$ shows the time series of $S_{\text {in, }}$, transportweighted outflow salinity without sea ice contribution
$\left(S_{\text {out }}^{o}\right)$, and $S_{\text {out }}^{o i}$. Their annual means $( \pm 1 \mathrm{std})$ are $34.57 \pm$ $0.18,34.10 \pm 0.07$, and $33.95 \pm 0.09$, respectively. Note that $S_{\text {in }}$ has a clear seasonal cycle, with low values of $\sim 34.4$ during summer and higher values of $\sim 34.7$ during winter, but $S_{\text {out }}^{o}$ has no clear seasonal cycle. Adding the sea ice contribution, this $S_{\text {out }}^{o}$ time variation is modulated during September to April, as seen in $S_{\text {out }}^{o i}$ time series.

Figure $11 \mathrm{~d}$ shows the time series of potential density in inflow $\left(D_{\text {in }}\right)$ and outflow without ice $\left(D_{\text {out }}^{o}\right)$ and with sea ice $\left(D_{\text {out }}^{o i}\right)$, which are calculated based on $\Theta_{\text {in }}, \Theta_{\text {out }}^{o}$, $\Theta_{\text {out }}^{o i}, S_{\text {in }}, S_{\text {out }}^{o}$, and $S_{\text {out }}^{o i}$. Annual means $( \pm 1 \mathrm{std})$ of $D_{\text {in }}$, $D_{\text {out }}^{o}$, and $D_{\text {out }}^{o i}$ are 27.51 $\pm 0.18,27.37 \pm 0.06$, and 27.28 \pm $0.06 \mathrm{~kg} \mathrm{~m}^{-3}$, respectively. The inflow $D_{\text {in }}$ has a seasonal cycle, with high values of $\sim 27.7 \mathrm{~kg} \mathrm{~m}^{-3}$ during winter and lower values of $\sim 27.4 \mathrm{~kg} \mathrm{~m}^{-3}$ during summer, reflecting 

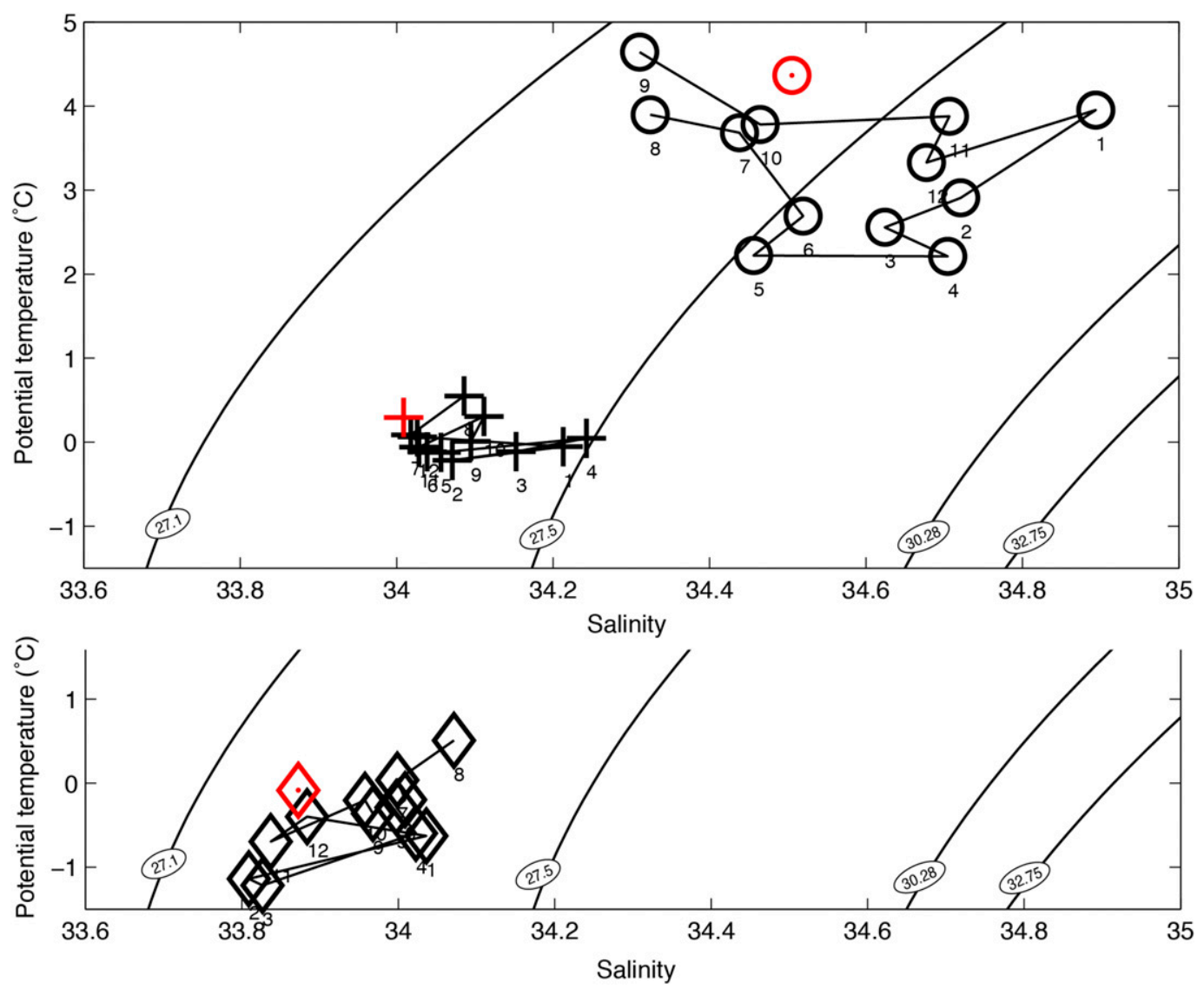

FIG. 12. (top) Volume transport weighted potential temperature $\left({ }^{\circ} \mathrm{C}\right)$ and salinity in inflow (circle) and outflow without sea ice (crossed) on $\theta-S$ space. Updated estimates of T2012 are shown as red symbols. Numbers below each symbol show numbers of months in the years. They start at month 9 (September 2005) and end at month 8 (August 2006) via month 11 (November 2005), month 1 (January 2006), and so on. Model water mass boundaries (densities) are shown in black. These corresponding densities are $27.1 \sigma_{0}, 27.5 \sigma_{0}, 30.28 \sigma_{0.5}$, and $32.75 \sigma_{1.0}$. (bottom) As in (top), but outflow properties are calculated including sea ice contribution plotted as diamonds. The inflow plots are trimmed to avoid the duplication.

the seasonal cycles of $\Theta_{\text {in }}$ and $S_{\text {in. }}$. Density variability is dominated by salinity variability at low temperatures when the salinity range is (relatively) large.

Figure 11e shows the monthly boundary heat fluxes (section 3d; Fig. 7b) along with the diagnosed time series based on (5). These two time series are very similar (as they should be). The boundary heat flux is higher $(\sim 220 \mathrm{TW})$ during September-January because of the larger temperature difference between $\Theta_{\text {in }}$ and $\Theta_{\text {out }}^{o i}\left(\sim 4^{\circ} \mathrm{C}\right)$ and stronger volume inflow $\left(V_{\text {in }} \sim 12 \mathrm{~Sv}\right)$. It is lower $(\sim 130 \mathrm{TW})$ during MarchJune because of the smaller temperature difference between $\Theta_{\text {in }}$ and $\Theta_{\text {out }}^{o i}$ of $\left(\sim 3^{\circ} \mathrm{C}\right)$ and weaker volume inflow $\left(V_{\text {in }} \sim 10 \mathrm{~Sv}\right)$.

Figure 11f shows the time series of net boundary FW flux (section 3e; Fig. 9b) along with the diagnosed time series from (6). The net FW flux is higher $(\sim 300 \mathrm{mSv})$ during early winter as a result of the larger salinity difference between $S_{\text {in }}$ and $S_{\text {out }}^{o i}(\sim 0.9)$ and stronger volume transports. It is lower $(\sim 150 \mathrm{mSv})$ during summer as a result of the smaller salinity difference between $S_{\text {in }}$ and $S_{\text {out }}^{o i}(\sim 0.4)$ and weaker volume transport.

We next view the net $\theta-S$ transformations of monthly inflows into outflows on $\theta-S$ space (Fig. 12). Considering first the all-liquid inflow, we note that the seasonal cycles of liquid seawater temperature and salinity are roughly in quadrature (i.e., $\sim 3$ months out of phase). Salinity extrema occur in summer (winter), which we associate with maximum (minimum) insolation causing maximum rates of melting (freezing). Temperature extrema occur in autumn (spring), when heat has ceased (begun) to be input to the ice and ocean. The effect is that the mean properties rotate (roughly) clockwise in $\theta-S$ phase space through the year. In contrast, the liquid outflow is more 
compressed in $\theta-S$ space, with the property ranges reduced compared with inflow values.

Based on the differences between the annual means of inflows and outflows, the annual mean net effect of the Arctic is to freshen and cool the inflows by $0.62 \pm 0.23$ in salinity (including sea ice) and $3.74^{\circ} \pm 0.76^{\circ} \mathrm{C}$, and there is a net input of surface buoyancy flux indicated by the decrease in mean density (including sea ice) of $0.23 \pm 0.20 \mathrm{~kg} \mathrm{~m}^{-3}$.

\section{Discussion}

In this section, we discuss the meaning and implications of the results presented in section 3. We have generated time series of 12 monthly values, spanning a year, of heat and FW fluxes around the defined Arctic ice and ocean boundary. We first consider the meaning of our results in the light of the absence of direct estimates of interior storage fluxes. We next compare our results with atmospheric reanalysis and the NEMO model.

\section{a. Fluxes and storage}

Storage fluxes of heat and FW are undoubtedly important in the Arctic Ocean, both on seasonal and longer time scales, but they cannot yet be estimated directly by means of in situ census. The technologies available to make year-round property measurements-moorings and ice-tethered profiling instruments-are not yet sufficiently spatially dense to resolve changes at the monthly to seasonal time scale. Alternatively, we can estimate the seasonal cycle of FW storage from measurements using remote-sensed altimetry and gravimetry in combination to calculate mass and steric contributions to total sea surface height changes (Giles et al. 2012). It is reasonable to approximate the seasonal cycle of FW storage, therefore, as the sum of two components: a repeating seasonal cycle of zero mean, and a long-term trend (Armitage et al. 2016, their Fig. 5). As a consequence, the annual average of the ice and ocean boundary FW flux accurately represents the annual average of the surface flux of $\mathrm{FW}$, when the long-term trend is included as a relatively small contribution to its uncertainty.

We can assert, by analogy, that the same holds true for heat storage within the control volume: the annual average of the ice and ocean boundary heat flux accurately represents the annual average of the surface heat flux. In reality, it is more difficult to justify this assertion with reference to measurements, because the focus of much recent work on storage has been on FW and not on heat. Some studies have taken a long-term view of Arctic temperature changes, such as Steele and Boyd (1998), Korhonen et al. (2013), and Polyakov et al. (2012, 2017). We make a scale calculation for the long-term heat storage flux as follows. Assume that $10 \%$ of the Arctic area is affected $\left(10^{12} \mathrm{~m}^{2}\right)$, and that a depth range of $500 \mathrm{~m}$ is warmed by $0.5^{\circ} \mathrm{C}$ over 10 years; with density $1000 \mathrm{~kg} \mathrm{~m}^{-3}$ and heat capacity $4000 \mathrm{~J} \mathrm{~kg}^{-1}{ }^{\circ} \mathrm{C}^{-1}$, the resulting heat flux is $3 \mathrm{TW}$, which is negligible.

We next consider the amplitudes of seasonal cycle in surface and boundary fluxes. Bacon et al. (2015) illustrate, using NEMO model output, the large disparity in the amplitudes between them: the surface heat flux amplitude is $\sim 500 \mathrm{TW}$ whereas the boundary amplitude $\sim 50$ TW. However, we note that almost all waters entering the Arctic take a very long time to reach an exit: from several years to decades, and even to centuries. For the surface and halocline waters, the transit times are between 2 and 16 years (Schlosser et al. 1999; Ekwurzel et al. 2001). For the Atlantic Water the time to travel along the Arctic margins until the Atlantic Water exits the Arctic Ocean through the western Fram Strait is $O(20)$ years (Mauldin et al. 2010; Karcher et al. 2011, 2012) and for the Pacific inflow the transit times are $O(10)$ years (e.g., Aksenov et al. 2016). The exception is the Fram Strait recirculation, where waters entering the volume on western side of the WSC may only spend weeks to months inside the control volume before leaving again as part of the EGC. Therefore the seasonal cycle of surface heat (and FW) flux is smoothed out during the long residence times within the control volume, through the application of many (maybe tens or even hundreds of) seasonal cycles.

These are our conclusions as to the meaning of the ice and ocean boundary fluxes. First, the annual mean boundary fluxes accurately represent the relevant annual mean surface fluxes, even in the absence of storage measurements. Second, we use the phrase "accurately represent" rather than "are equal to" because the boundary fluxes are the result of a complex convolution of the trajectories of individual water parcels with the action of surface fluxes upon them over many years. Third, the individual monthly boundary fluxes do not represent surface fluxes, in the absence of storage measurements.

\section{b. Comparison with atmospheric reanalysis and NEMO model}

The annual mean $( \pm 1 \mathrm{std})$ boundary heat flux estimate is $175 \pm 48 \mathrm{TW}$, equivalent to $15.5 \pm 4.2 \mathrm{~W} \mathrm{~m}^{-2}$ within the boundary. Mayer et al. (2016) show that the Arctic Ocean has accumulated heat at rate of $\sim 1 \mathrm{~W} \mathrm{~m}^{-2}$ during 2000-15, primarily based on various reanalysis products of ocean and sea ice. Assuming that month-tomonth heat storage variability becomes negligible by averaging over a year, the sum of boundary heat flux $\left(15.5 \pm 4.2 \mathrm{~W} \mathrm{~m}^{-2}\right)$ and Arctic heat content change $\left(\sim 1 \mathrm{~W} \mathrm{~m}^{-2}\right)$ should be equal to long-term average 
surface net heat fluxes. Porter et al. (2010) and Cullather and Bosilovich (2012) update Serreze et al.'s (2007b) atmospheric heat budget estimate with atmospheric reanalysis output and satellite-based estimates. Note that their estimates refer to the polar cap north of $70^{\circ} \mathrm{N}$, and they include most of the Nordic Seas, where large surface heat flux happens. Their long-term mean surface heat fluxes range from $5 \mathrm{~W} \mathrm{~m}^{-2}$ for the NCEP-NCAR Reanalysis (NRA; Kalnay et al. 1996), $11 \mathrm{~W} \mathrm{~m}^{-2}$ for the ECMWF Reanalysis (ERA-40; Uppala et al. 2005), $14 \mathrm{~W} \mathrm{~m}^{-2}$ for the contemporary Climate Forecast System Reanalysis (CFSR; Saha et al. 2010), to $19 \mathrm{~W} \mathrm{~m}^{-2}$ for the Modern-Era Retrospective Analysis for Research and Applications (MERRA; Cullather and Bosilovich 2012). CFSR and MERRA are closest to our estimate.

We do similar assessment on surface FW flux. The annual mean ( $\pm 1 \mathrm{std})$ boundary FW flux is $204 \pm 85 \mathrm{mSv}$ $\left(6430 \pm 2680 \mathrm{~km}^{3} \mathrm{yr}^{-1}\right)$. The long-term trend of $\mathrm{FW}$ content increase within the side boundary is estimated as $\sim 10 \mathrm{mSv}\left(\sim 315 \mathrm{~km}^{3} \mathrm{yr}^{-1}\right)$, considering the recent liquid FW content increase during 1992-2012 (Rabe et al. 2014) and the decline of sea ice over the last decades (Lindsay and Schweiger 2015). The sum of them agrees well with the surface FW flux estimate of Haine et al. (2015) of $6770 \mathrm{~km}^{3} \mathrm{yr}^{-1}$ for the period of 2000-10, which is the sum of river runoff of $4200 \pm 420 \mathrm{~km}^{3} \mathrm{yr}^{-1}$ ( \pm uncertainty), excess of precipitation over evaporation of $2200 \pm 220 \mathrm{~km}^{3} \mathrm{yr}^{-1}$ ( \pm uncertainty), and FW input from Greenland into the Baffin Bay of $370 \pm 25 \mathrm{~km}^{3} \mathrm{yr}^{-1}$ ( \pm uncertainty). The agreement is very good, even though about one-third of the Arctic FW runoff volume is ungauged (Shiklomanov and Lammers 2009). Precipitation estimates differ in the seven most recent atmospheric reanalysis models (Lindsay et al. 2014), and this is one of the key processes in the atmosphere that requires better quantification and understanding to enable better predictions of the Arctic freshwater system (Vihma et al. 2016).

Pemberton et al. (2015) provide another useful point of comparison by diagnosing annual-mean water mass transformations in a low-resolution $\left(1^{\circ}\right)$ version of the NEMO model run. They use a similar domain to ours, with gateways at the Bering and Fram Straits and the BSO; however, instead of Davis Strait, they close the boundary at the model's Barrow and Nares Straits, in the Canadian Arctic Archipelago, thereby omitting Baffin Bay, for which we must make some allowance. Their transport-weighted inflow and outflow temperatures, salinities, and densities (compared with ours) are $T_{\text {in }}=2.9^{\circ}\left(3.3^{\circ} \mathrm{C}\right)$ and $T_{\text {out }}^{o}=-0.7^{\circ}\left(0.0^{\circ} \mathrm{C}\right), S_{\text {in }}=34.3$ (34.6) and $S_{\text {out }}^{o}=33.6(34.1)$, and $D_{\text {in }}=27.34 \mathrm{~kg} \mathrm{~m}^{-3}$ $\left(27.51 \mathrm{~kg} \mathrm{~m}^{-3}\right)$ and $D_{\text {out }}^{o}=27.01 \mathrm{~kg} \mathrm{~m}^{-3}\left(27.37 \mathrm{~kg} \mathrm{~m}^{-3}\right)$. Thus, Pemberton et al. (2015) cool and freshen the inflow by $3.6^{\circ} \mathrm{C}$ and 0.7 , compared with our $3.3^{\circ} \mathrm{C}$ and 0.5 (respectively), resulting in a density change (toward lower density) of $0.33 \mathrm{~kg} \mathrm{~m}^{-3}$, more than double our estimate of $0.14 \mathrm{~kg} \mathrm{~m}^{-3}$, which results mainly from their stronger freshening. Overfreshening of outflows could have important downstream consequences for the meridional overturning circulation (MOC), for example. The omission by Pemberton et al. (2015) of Baffin Bay makes little difference to these property changes because Baffin Bay is only $\sim 5 \%$ of our domain's total surface area, while its surface heat (Aksenov et al. 2010a) and FW fluxes (Haine et al. 2015) are similar to Arctic net values.

\section{Summary}

We have presented, for the first time, the seasonal variability of Arctic ice and ocean boundary heat and FW fluxes, expressed as 12 monthly mean fluxes from September 2005 to August 2006 (Figs. 7 and 9; Table 3). Their annual means $( \pm 1 \mathrm{std})$ are $175 \pm 48 \mathrm{TW}$ and $204 \pm$ $85 \mathrm{mSv}$, and they include sea ice contributions of $22 \pm$ $15 \mathrm{TW}$ and $48 \pm 32 \mathrm{mSv}$ respectively. They compare reasonably well with models, reanalysis, and data compendia. Furthermore, these annual mean boundary fluxes accurately represent annual mean surface fluxes, when the long-term trend is included as a relatively small contribution to its uncertainty. They are the first (almost) entirely measurement-based estimates of these quantities.

The boundary heat flux variability derives mainly from velocity variability in the AW layer and temperature variability in the surface layer (Table 5). We represent unobserved variability in the upper $50 \mathrm{~m}$ and over shelf regions with model output, but this affects the net ocean heat transport by less than $7 \mathrm{TW}(5 \%$ of the total ocean heat transport; Fig. 10a). We find that the FW flux variability is dominated by Bering Strait FW transport variability, which in turn is dominated by its velocity variability (Fig. 9a; Table 6). The ocean FW transport uncertainties stem mainly from the unobserved variability in the upper $50 \mathrm{~m}$ in western Davis Strait, Belgica Bank variability in Fram Strait, and sparse salinity measurements in the EGC region in Fram Strait (Figs. 10b-e). We estimate that their uncertainties are each $\sim 30 \mathrm{mSv}$-eq (19\% of the total ocean FW transport). Improved observations in these regions would reduce uncertainty in FW transport estimates.

The boundary flux estimates are converted into associated water mass property changes, as transport-weighted temperature and salinity variability in the inflow and outflow (Figs. 11 and 12). Inflow temperature and salinity have clear seasonal cycles but different phase, while outflow temperature varies little, and outflow salinity has no clear seasonal cycle. The annual net effect of the Arctic is to 
freshen and cool the inflows by $0.62 \pm 0.23$ in salinity and $3.74^{\circ} \pm 0.76^{\circ} \mathrm{C}$ in temperature, with a resulting net input of buoyancy shown by the decrease in mean density of $0.23 \pm 0.20 \mathrm{~kg} \mathrm{~m}^{-3}$.

Acknowledgments. This study was funded by the UK Natural Environment Research Council as a contribution to the Arctic project TEA-COSI (NE/I028947/1, PI Bacon). The Davis Strait mooring data were collected by UW, Seattle, USA (PI Lee) with funding from NSF Grant ARC-1022472. The data and objectively mapped sections are available via http://iop.apl.washington.edu/data.html. The Bering Strait mooring data were collected by UW, Seattle, the USA and the UAF, Fairbanks, the USA (PIs Woodgate and Weingartner) with funding from NSF Grant NFS-0856786 and the NOAA-RUSALCA program. The data are freely available via http://psc.apl. washington.edu/BeringStrait.html. The BSO mooring data were collected by IMR, Bergen, Norway (PI Ingvaldsen). The Fram Strait mooring data were collected by AWI, Bremerhaven, Germany, and NPI, Troms $\emptyset$, Norway (PIs Schauer and Hansen). The central and eastern Fram Strait mooring data are available via https://doi.pangaea.de/10.1594/PANGAEA.845938. The BSO and western Fram Strait mooring data is available on request. The volume, heat, and FW transport time series presented in this study can be accessed via https://doi. pangaea.de/10.1594/PANGAEA.870607. "DOBOX 4.2" (Morgan 1995) is used for the box inverse model. We thank Dr. Jullion for constructive discussions on the box inverse model. Support for this work was provided by the EU's Horizon 2020 Marie Skłodowska-Curie Grant Agreement 652757 (Tsubouchi).

\section{APPENDIX A}

\section{The Box Inverse Model}

This appendix provides an overview of the box inverse models, settings of the model unknowns, constraints, and a priori uncertainties, initialization of the unknowns, and the box inverse modification.

\section{a. Overview of the box inverse models}

The problem is represented by an equation,

$$
\mathbf{A} \mathbf{b}^{u}=\mathbf{d}+\boldsymbol{\varepsilon},
$$

where $\mathbf{b}^{u}$ is an $n \times 1$ vector ( $n$ rows, 1 column) and contains the four different sets of unknowns, comprising reference velocity, diapycnal velocity, sea ice advection speed, and surface FW flux. The $(m \times n)$ matrix A contains information about the geometry of the system and has one row for each constraint. The $(m \times 1)$ vector d contains information about values to which the system is to be constrained. This is calculated as $\mathbf{d}=\mathbf{A} \mathbf{b}^{i}$. The quantity $\mathbf{b}^{i}$ is an $(n \times 1)$ vector and it contains initial estimates for the unknowns. During the initialization process, our prior knowledge on the unknowns is provided as first guess. The $(m \times 1)$ vector $\varepsilon$ is an error vector. The vector $\mathbf{b}^{u}$ can be derived by solving the matrix equation [(A1)]. Final values for the assigned unknowns $\left(\mathbf{b}^{f} ; n \times 1\right.$ vector) are obtained as $\mathbf{b}^{f}=\mathbf{b}^{i}+\mathbf{b}^{u}$. It satisfies the prescribed constrains in the matrix equation. For the inversion, we employ the software suite "DOBOX 4.2" (Morgan 1995), modified accordingly to incorporate some extra unknowns.

Before the inversion, row and column weighting are applied to the $(m \times n)$ matrix A. The $(m \times m)$ row weighting matrix $\mathbf{W}$ carries prior knowledge on transport uncertainty. The $(n \times n)$ column weighting matrix $\mathbf{E}$ carries uncertainties on each unknowns. Equation (A1) can be transformed into a weighted system,

$$
\mathbf{A}^{\prime} \mathbf{b}^{\prime \prime}=\mathbf{d}^{\prime}+\boldsymbol{\varepsilon}^{\prime},
$$

where $\mathbf{A}^{\prime}=\mathbf{W A E}, \mathbf{b}^{\prime u}=\mathbf{E}^{-1} \mathbf{b}^{u}, \mathbf{d}^{\prime}=\mathbf{W d}$ and $\boldsymbol{\varepsilon}^{\prime}=\mathbf{W} \boldsymbol{\varepsilon}$.

We choose to solve the system $\mathbf{A}^{\prime} \mathbf{b}^{\prime \prime}=\mathbf{d}^{\prime}$ using a truncated singular value decomposition (SVD). The $(m \times n) \mathbf{A}^{\prime}$ matrix can be decomposed into the SVD form, $\mathbf{A}^{\prime}=\mathbf{U} \mathbf{\Lambda} \mathbf{V}^{\mathrm{T}}$, where the $(m \times k) \mathbf{U}$ matrix and the $(n \times k) \mathbf{V}$ matrix contain orthogonal eigenvectors, $\boldsymbol{\Lambda}$ is the $(k \times k)$ diagonal matrix of eigenvalues, and $k$ is the rank of SVD. The solution for the equation $\mathbf{A}^{\prime} \mathbf{b}^{\prime u}=\mathbf{d}^{\prime}$ is obtained as $\mathbf{b}^{\prime u}=\left(\mathbf{V} \boldsymbol{\Lambda}^{-1} \mathbf{U}^{\mathrm{T}}\right) \mathbf{d}^{\prime}$ by left-multiplication by $\left(\mathbf{U} \boldsymbol{\Lambda} \mathbf{V}^{\mathrm{T}}\right)^{-1}$. The solution for the equation $\mathbf{A} \mathbf{b}^{u}=\mathbf{d}$ is obtained as $\mathbf{b}^{u}=\mathbf{E b}^{\prime u}$.

It is worth noting that the problem is an underdetermined system (i.e., there are more unknowns than constraints; $n>m$ ). If the full rank solution of SVD were used, all the equations would be satisfied exactly. However, we know that the equations contain uncertainties $\varepsilon$, the size of which can be estimated. To satisfy the equations exactly using the full rank solution would introduce larger modifications, and there is no justification to do so given the uncertainties in the constraints.

Both in T2012 and this study, surface heat flux is not an unknown parameter of the box inverse model because we do not constrain heat fluxes. Rather, the annual mean surface heat flux is diagnosed using the obtained boundary ocean and sea ice velocity and temperature fields (see section 4 a for detail).

\section{b. Setting of the box inverse model}

There are 1287 unknowns to be determined by the inverse model. The horizontal resolution of $3 \mathrm{~km}$ requires 
639 values of reference velocities to be determined, and the same number of values of sea ice velocity. There are four layer interfaces where diapycnal transports of volume and salinity velocity are to be determined. The surface FW flux is one further unknown.

The following flux constraints are applied: full depth conservation of volume and salinity transports (1 constraint each), and volume and salinity transports for each layer ( 5 constraints for each), with a total of 12 constraints. We prescribe salinity conservation instead of salinity anomaly conservation because the model solution can be distorted by large FW transport imbalances appearing in salinity anomaly constraints, whereas salinity constraints generate stable solutions.

Weighting matrices are applied to rows (constraints) and columns (unknowns): $\mathbf{W}(m \times m)$, and $\mathbf{E}(n \times n)$ (respectively), where $m$ and $n$ are the numbers of conservation equations (12) and unknowns (1287), respectively. They are nonzero only on the diagonal components of the matrices. We specify here the differences from T2012 resulting from the use of salinity constraints. For property transports, for layer $i, W_{i i}=1 /\left(2 \eta_{i}^{C} \varepsilon_{i} \Gamma_{i}\right)$, where $\varepsilon_{i}$ is the layer a priori volume transport uncertainty, $\eta_{i}^{C}$ is the layer standard deviation of variations of property $C$, and $\Gamma_{i}$ is layer property mean. The latter is introduced to balance volume and salinity constraints. A priori layer transport uncertainties and property means and standard deviations are listed in Table A1.

Column weights take the same form as in T2012 (i.e., a velocity parameter scaled by an area parameter) as appropriate to the relevant variable. One exception is that salinity scaling [used by T2012 in sea ice velocity and surface FW flux weights in their (16) and (17)] is removed due to the present use of salinity rather than salinity anomaly. The a priori reference velocity uncertainty is estimated as the 3-month standard deviation of moored velocity measurements $\left(0.01-0.05 \mathrm{~m} \mathrm{~s}^{-1}\right)$. Uncertainties are linearly interpolated onto each grid accordingly. Following T2012, larger a priori uncertainties are associated with Belgica Bank $\left(0.06 \mathrm{~m} \mathrm{~s}^{-1}\right)$ and the northern $\mathrm{BSO}$, where moored velocity measurements are lacking. Bering Strait uncertainties are set to $10 \%$ of the 3-month standard deviation $\left(\sim 0.02 \mathrm{~m} \mathrm{~s}^{-1}\right)$, to take into account its larger short-term variability (Woodgate et al. 2005). The a priori uncertainty in the diapycnal velocities is set to $1 \times 10^{-5} \mathrm{~m} \mathrm{~s}^{-1}$, near the upper end of the range of vertical velocities inferred from observed ocean mixing rates (Rippeth et al. 2015). The a priori uncertainty in the sea ice advection velocity is set to $10 \%$ magnitude of its initial estimate when sea ice thickness is greater than $0.3 \mathrm{~m}$. When it is less than $0.3 \mathrm{~m}$, the a priori uncertainty is set to zero to avoid large column weightings. The a priori
TABLE A1. A priori uncertainties in volume conservation, mean, and standard deviation of potential temperature and salinity in each defined layer. The mean and standard deviation are based on estimates for 12 months.

\begin{tabular}{cccc}
\hline \hline $\begin{array}{c}\text { Model } \\
\text { layer }\end{array}$ & $\begin{array}{c}\text { Uncertainty } \\
(\mathrm{Sv})\end{array}$ & $\begin{array}{c}\text { Potential } \\
\text { temperature } \\
\left({ }^{\circ} \mathrm{C}\right)\end{array}$ & $\begin{array}{c}\text { Salinity } \\
\left(\mathrm{g} \mathrm{kg}^{-1}\right)\end{array}$ \\
\hline 1 & 6.0 & $1.89 \pm 3.76$ & $33.44 \pm 0.83$ \\
2 & 4.0 & $2.75 \pm 3.19$ & $34.37 \pm 0.43$ \\
3 & 3.0 & $2.75 \pm 2.38$ & $34.80 \pm 0.28$ \\
4 & 2.0 & $0.49 \pm 1.36$ & $34.87 \pm 0.14$ \\
5 & 1.0 & $-0.78 \pm 0.69$ & $34.87 \pm 0.07$ \\
6 & 0.1 & $1.85 \pm 2.87$ & $34.21 \pm 0.94$ \\
\hline
\end{tabular}

uncertainty of surface FW input is set to $100 \%$ magnitude of its initial estimate.

\section{c. Initialization of the box inverse model}

All unknowns are initialized as follows. Reference velocities on each grid point are initialized using moored velocity measurements, vessel mounted acoustic Doppler current profiler (VMADCP) data over Belgica Bank (Rabe et al. 2009), or NEMO modeled velocities with linear interpolation. Sea ice initial velocities are derived from PIOMAS monthly output by projection onto the inverse model grid. Diapycnal velocities are set to zero. The initial surface FW flux is set to $180 \mathrm{mSv}$ throughout the year, followed by T2012's initialization river runoff of $100 \mathrm{mSv}$, and precipitation minus evaporation of $65 \mathrm{mSv}$ from Serreze et al. (2006), and Baffin Bay total FW input of $15 \mathrm{mSv}$. We set constant surface FW flux because we aim to diagnose this term from boundary measurements using the box inverse model.

\section{d. Box inverse model modification}

For each of the 12 months, the row- and columnweighted system of equations [(A2)] is solved by the SVD. The solution rank (8, out of 12 constraint equations) is selected to yield a stable solution in which perturbations to initial estimates of unknowns remain within a priori uncertainties. Overall, reference velocities are modified by mean (peak) perturbations of $2(10) \mathrm{mm} \mathrm{s}^{-1}$. The largest adjustments are introduced where observations are lacking, over Belgica Bank and north of Bear Island. Sea ice mean (peak) advection velocity adjustments are $2(10) \mathrm{mm} \mathrm{s}^{-1}$, equivalent to 0.5 -mSv adjustments on average. The mean adjustment of surface FW flux is $20 \pm 88 \mathrm{mSv}$, with a peak of $150 \mathrm{mSv}$. The diagnosed diapycnal velocities have median values of $1-3 \times 10^{-7} \mathrm{~ms}^{-1}$.

After the inversion, the annual mean and standard deviation of residual imbalances of volume, salinity anomaly and temperature transport anomaly in each 
layer are examined. Full-depth volume and salinity imbalances are closed in each individual month, within 0.1 and $1 \mathrm{mSv}$, respectively. Volume transport imbalances by layer are indistinguishable from zero from a priori uncertainties (Table 4). A substantial salinity transport imbalance of $2.3 \mathrm{~Sv}$ as 12 monthly average, equivalent to $66 \mathrm{mSv}$ of FW, remains in layer 1. This is balanced by the sum of layers 2 and 3. This structure is also seen in T2012. All of the surface FW flux is input into layer 1 in the inverse model, because we do not know the spatial distribution of surface FW inputs and their relationship to layer outcrops.

Most of the volume transport imbalances in each month are adjusted in Fram Strait and the BSO. The annual mean and standard deviation of the total transport adjustments are $-1.0 \pm 3.1 \mathrm{~Sv}$; for each gateway, they are $-0.1 \pm 0.2 \mathrm{~Sv}$ (Davis Strait), $-0.5 \pm 2.2 \mathrm{~Sv}$ (Fram Strait), $-0.4 \pm 0.7 \mathrm{~Sv}$ (BSO), and $0.0 \pm 0.0 \mathrm{~Sv}$ (Bering Strait). The annual mean and standard deviation of $\mathrm{FW}$ transport adjustments is $3 \pm 6 \mathrm{mSv}$-eq; oceanic adjustment does not play a major role on resolving the initial FW transport imbalances.

\section{APPENDIX B}

\section{Uncertainty of the Total Ocean Heat and FW Transports}

We examine the robustness of the total ocean heat and FW transports by investigating (first) the impact of the NEMO model output, where it is used to fill unobserved regions (the upper $50 \mathrm{~m}$, and over the shallow shelves), and (second) the sparseness of the salinity measurements in Fram Strait.

To quantify the impact of NEMO, four different sets of monthly temperature, salinity, and velocity fields are prepared. The first is called "MooringOnly" and uses no NEMO output, so we assume no stratification above the shallowest instruments, which means the upper $100 \mathrm{~m}$ in central Davis Strait and the upper $50 \mathrm{~m}$ in Fram and Bering Strait. For the shelves (Belgica Bank in Fram Strait and Bjørnøya Bank in BSO), we put zero velocities. For temperature and salinity over the shelves, we apply uniform temperature and salinity profiles over the region. The second is the "BestEstimate" dataset, as prepared in section $2 \mathrm{~b}$. The third is called "Inc50mNoShelf", and it includes the upper ocean variability in Davis, Fram and Bering Straits, but it does not have shelf region variability. The fourth is the "No50mIncShelf" estimate; it has no upper-ocean temperature, salinity, or velocity variability (outside the shelf regions), but it includes the shelf region variability. Inversions with volume and salinity constraints for each layer and for full depth (as described in appendix A) are performed to obtain volumeand salinity-conserved velocity fields for all datasets.

Ocean heat transports (Fig. 10a) are relatively insensitive to our permutations, with a range of approximately \pm 5 TW per month ( \pm uncertainty). For ocean FW transports (Fig. 10b), the shape of the month-to-month variability is similar across the various permutations, which means that the moored observations alone capture the majority of the FW transport seasonal cycle. However, there is a mean offset between the BestEstimate and MooringOnly runs of $6 \pm 13 \mathrm{mSv}$. This is a result of competition between the impacts of the upper $50 \mathrm{~m}$, where the Inc50mNoshelf runs add $34 \mathrm{mSv}$ on average to the MooringOnly estimates, and of the shelf waters, where the No50mIncShelf runs subtract $26 \mathrm{mSv}$. To investigate the source of these offsets, we inspect the cumulative FW transport anomaly (with respect to the MooringOnly runs) around the boundary (Fig. 10c). The positive contribution to the FW transport from the upper $50 \mathrm{~m}$ almost entirely occurs in western Davis Strait (33 $\pm 7 \mathrm{mSv}$-eq). Inclusion of Belgica Bank via the No50mIncShelf run has a substantial impact: the recirculation over the bank has an amplitude of $\sim 60 \mathrm{mSv}$ eq, but it leaves a residual contribution to the FW transport of $-27 \pm 6 \mathrm{mSv}$-eq. Improved observations in these regions would lead to better estimates of FW transports.

Next, we examine the impact on FW transports of the sparseness of the salinity measurements in Fram Strait by conducting a suite of sensitivity tests. Four different monthly sets of Fram Strait temperature and salinity fields are prepared as follows. First, an annual mean salinity section is generated from the monthly BestEstimate fields; this is called "MooringTSfix." Second, we use the monthly BestEstimate dataset itself. Third, we use the high-resolution, full-depth, hydrographic temperature and salinity fields from T2012, fixed throughout the year; this is called "T2012TSfix." Fourth, we generate high-resolution, time-varying temperature and salinity fields by temporal extrapolation through the year, starting with the T2012 temperature and salinity fields, and using the NEMO salinity temporal variability; this is the "T2012TSvar" estimate. Figure 10d shows the four resulting sets of net ocean FW transports across the pan-Arctic boundary. All the time series show similar seasonal cycles in terms of phase and magnitude. The major difference arises between pairs of runs. For one pair, there is little difference between use of the annual mean salinity section versus monthly salinity fields (MooringTSfix and BestEstimate). For the other pair, there is little difference between the use of the fixed T2012 salinity field and the same field with added NEMO temporal variability. 
However, there is a difference between the pairs of $\sim 30 \mathrm{mSv}$, with the fields using T2012 salinity generating lower FW transport. Figure 10e shows that the discrepancy comes from EGC region in Fram Strait. This is primarily due to sparse mooring measurements, which fail to capture the halocline layer between 50- and 150-m water depth in the region. Comparison of the September 2005 mooring salinity section with the CTD section from 26 August to 9 September 2005 highlights up to 1.0 salinity discrepancy in depths of 50-200 $\mathrm{m}$ in the region, where the mooring salinities appear too fresh. The mooring array fails to capture the salinity 34.5 halocline layer at depths of $50-150 \mathrm{~m}$, so that fresher water is present as a result of the linear interpolation. More salinity observations in the EGC region (50-500 m) would lead to better estimates of FW transport. We suggest that ocean FW transport uncertainty associated with sparse salinity measurements in Fram Strait is $\sim 30 \mathrm{mSv}$.

\section{APPENDIX C}

\section{Deviation of Transport-Weighted Mean Properties Associated with the Water Mass Transformation}

Monthly velocity fields on geographical coordinate (distance against pressure) are transformed into a $\theta-S$ plane, gridded with $d \theta=0.2^{\circ} \mathrm{C}$ and $d S=0.05$. All transports within the same $\theta-S$ grid box are summed and the net transports in the class are calculated. Calculated net volume transports $\left(\mathrm{m}^{3} \mathrm{~s}^{-1}\right)$ binned in $\theta-S$ class are stored in $\Pi(\theta, S)$.

Using the $\Pi(\theta, S)$, inflow volume transport associated with the water mass transformation $\left(V_{\text {in }}\right)$ is calculated as

$$
V_{\text {in }}=\iint \delta_{\text {in }} \Pi(\theta, S) d \theta d S,
$$

where $\delta_{\text {in }}(\theta, S)$ is a boxcar function. It is 1 when $\Pi(\theta, S)$ is positive, and it is 0 when $\Pi(\theta, S)$ is negative. Here $d \theta$ is a potential temperature element and $d S$ is a salinity element on the $\theta-S$ plane.

Volume transport weighted potential temperature in inflow $\left(\Theta_{\text {in }}\right)$ and volume transport weighted salinity in inflow $\left(S_{\text {in }}\right)$ are calculated as

$$
\begin{gathered}
\Theta_{\text {in }}=\frac{1}{V_{\text {in }}} \iint \theta \delta_{\text {in }} \Pi(\theta, S) d \theta d S, \quad \text { and } \\
S_{\text {in }}=\frac{1}{V_{\text {in }}} \iint S \delta_{\text {in }} \Pi(\theta, S) d \theta d S .
\end{gathered}
$$

Outflow volume transport associated with the water mass transformation without sea ice $\left(V_{\text {out }}^{o}\right)$ and with sea ice $\left(V_{\text {out }}^{o i}\right)$ are calculated as

$$
\begin{aligned}
V_{\text {out }}^{o} & =\iint \delta_{\text {out }} \Pi(\theta, S) d \theta d S, \quad \text { and } \\
V_{\text {out }}^{o i} & =V_{\text {out }}^{o}+V_{\text {out }}^{i},
\end{aligned}
$$

where $\delta_{\text {out }}(\theta, S)$ is a boxcar function. It is 1 when $\Pi(\theta, S)$ is negative, and it is 0 when $\Pi(\theta, S)$ is positive. The $V_{\text {out }}^{i}$ is net sea ice export through the four Arctic main gateways in each month.

Volume transport weighted potential temperature in outflow without sea ice $\left(\Theta_{\text {out }}^{o}\right)$ and with sea ice $\left(\Theta_{\text {out }}^{o i}\right)$ are calculated as

$$
\begin{aligned}
\Theta_{\text {out }}^{o}= & \frac{1}{V_{\text {out }}^{o}} \iint \theta \delta_{\text {out }} \Pi(\theta, S) d \theta d S, \text { and } \\
\Theta_{\text {out }}^{o i}= & \frac{1}{V_{\text {out }}^{o}+V_{\text {out }}^{i}}\left[\iint \theta \delta_{\text {out }} \Pi(\theta, S) d \theta d S\right. \\
& \left.+\frac{\rho_{i} c_{p}^{i}}{\rho_{o} c_{p}^{o}}\left(-\frac{c_{f}}{c_{p}^{i}}+\theta^{i}\right) V_{\text {out }}^{i}\right]
\end{aligned}
$$

where $\theta^{i}$ is averaged sea ice temperature crossing through the four Arctic main gateways in each month. Also, $\rho_{o}$ is density of seawater $\left(1027 \mathrm{~kg} \mathrm{~m}^{-3}\right), c_{p}^{o}$ is specific heat capacity of seawater $\left(3.987 \times 10^{3} \mathrm{~J} \mathrm{~kg}^{-1} \mathrm{~K}^{-1}\right)$, $\rho_{i}$ is density of sea ice $\left(930 \mathrm{~kg} \mathrm{~m}^{-3}\right), c_{p}^{i}$ is specific heat capacity of sea ice from Ono (1967) as a function of sea ice temperature and salinity, and $c_{f}$ is heat of fusion $\left(3.347 \times 10^{5} \mathrm{~J} \mathrm{~kg}^{-1}\right)$.

In a similar manner, volume transport weighted salinity in outflow without sea ice $\left(S_{\text {out }}^{o}\right)$ and with sea ice $\left(S_{\text {out }}^{o i}\right)$ are calculated as

$$
\begin{aligned}
& S_{\text {out }}^{o}=\frac{1}{V_{\text {out }}^{o}} \iint S \delta_{\text {out }} \Pi(\theta, S) d \theta d S, \text { and } \\
& S_{\text {out }}^{o i}=\frac{1}{V_{\text {out }}^{o}+V_{\text {out }}^{i}}\left[\iint S \delta_{\text {out }} \Pi(\theta, S) d \theta d S+S_{i} V_{\text {out }}^{i}\right],
\end{aligned}
$$

where $S_{i}$ is sea ice salinity crossing through the Arctic main gateways in each month, which is set as 6 throughout the year.

Volume, heat, and salt conservation equations in the Arctic Ocean enclosed by the Arctic main gateways can be described using above defined quantities $[(\mathrm{C} 1)-(\mathrm{C} 6)]$ as

$\frac{\partial}{\partial t}\left(\sum \mathfrak{B}^{o i}\right)=\left(V_{\text {in }}-V_{\text {out }}^{o i}\right)+F_{\mathrm{FW}}^{\text {surf }}$,

$\frac{\partial}{\partial t}\left(\sum \mathcal{H}^{o i}\right)=\left(\rho_{o} c_{p}^{o} V_{\text {in }} T_{\text {in }}-\rho_{o} c_{p}^{o} V_{\text {out }}^{o i} \Theta_{\text {out }}^{o i}\right)+F_{H}^{\text {surf }}, \quad$ and 


$$
\frac{\partial}{\partial t}\left(\sum \Im^{o i}\right)=V_{\text {in }} S_{\text {in }}-V_{\text {out }}^{o i} S_{\text {out }}^{o i}
$$

where $\sum \mathfrak{B}^{o i}$ is total volume of in seawater and sea ice in the Arctic Ocean enclosed by the boundary, $F_{\mathrm{FW}}^{\text {surf }}$ is surface FW flux, $\sum \mathcal{H}^{o i}$ is the heat stored in the iceocean system within the boundary, and $F_{H}^{\text {surf }}$ is air-sea surface heat flux. Note that heat flux associated with the surface FW input is omitted as it is negligible. Also, $\sum \Im^{o i}$ is the salt stored in the ice-ocean system within the boundary.

Based on (C7)-(C9), $F_{\mathrm{vol}}^{\text {surf }}$ and $F_{H}^{\text {surf }}$ can be expressed as

$$
F_{H}^{\text {surf }}=-\rho_{o} c_{p}^{o}\left(\Theta_{\text {in }}-\Theta_{\text {out }}^{o i}\right) V_{\text {in }}+\frac{\partial}{\partial t}\left(\sum \mathcal{H}^{o i}\right), \quad \text { and }
$$

$$
F_{\mathrm{FW}}^{\text {surf }}=\frac{1}{S_{\text {out }}^{o i}}\left(S_{\text {in }}-S_{\text {out }}^{o i}\right) V_{\text {in }}+\frac{\partial}{\partial t}\left(\sum \mathfrak{B}^{o i}\right)-\frac{1}{S_{\text {out }}^{o i}}\left[\frac{\partial}{\partial t}\left(\sum \Im^{o i}\right)\right] .
$$

\section{REFERENCES}

Aksenov, Y., S. Bacon, A. C. Coward, and N. P. Holliday, 2010a: Polar outflow from the Arctic Ocean: A high resolution model xstudy. J. Mar. Syst., 83, 14-37, https://doi.org/ 10.1016/j.jmarsys.2010.06.007.

$\longrightarrow,-,-$, and A. J. G. Nurser, 2010b: The North Atlantic inflow to the Arctic Ocean: High-resolution model study. J. Mar. Syst., 79, 1-22, https://doi.org/10.1016/j.jmarsys.2009.05.003.

—, V. V. Ivanov, A. J. G. Nurser, S. Bacon, I. V. Polyakov, A. C. Coward, A. C. Naveira Garabato, and A. BeszczynskaMoeller, 2011: The Arctic Circumpolar Boundary Current. J. Geophys. Res., 116, C09017, https://doi.org/10.1029/ $2010 \mathrm{JC} 006637$.

— , and Coauthors, 2016: Arctic pathways of Pacific Water: Arctic Ocean Model Intercomparison experiments. J. Geophys. Res Oceans, 121, 27-59, https://doi.org/10.1002/2015JC011299.

Armitage, T. W. K., S. Bacon, A. L. Ridout, S. F. Thomas, Y. Aksenov, and D. J. Wingham, 2016: Arctic sea surface height variability and change from satellite radar altimetry and GRACE, 2003-2014. J. Geophys. Res., 121, 4303-4322, https://doi.org/10.1002/2015JC011579.

$\longrightarrow,-,-$ A. A. Petty, S. Wolbach, and M. Tsamados, 2017: Arctic Ocean surface geostrophic circulation 2003-2014. Cryosphere, 11, 1767-1780, https://doi.org/10.5194/tc-11-1767-2017.

Bacon, S., 1997: Circulation and fluxes in the North Atlantic between Greenland and Ireland. J. Phys. Oceanogr., 27, 1420-1435, https://doi.org/10.1175/1520-0485(1997)027<1420: CAFITN $>2.0 . \mathrm{CO} ; 2$.

—, A. Marshall, N. P. Holliday, Y. Aksenov, and S. R. Dye, 2014: Seasonal variability of the East Greenland Coastal Current. J. Geophys. Res. Oceans, 119, 3967-3987, https://doi.org/ 10.1002/2013JC009279.

, Y. Aksenov, S. Fawcett, and G. Madec, 2015: Arctic mass, freshwater and heat fluxes: Methods and modelled seasonal variability. Philos. Trans. Roy. Soc., 373, 20140169, https://doi.org/ 10.1098/rsta.2014.0169.
Beszczynska-Möller, A., E. Fahrbach, U. Schauer, and E. Hansen, 2012: Variability in Atlantic water temperature and transport at the entrance to the Arctic Ocean, 1997-2010. ICES J. Mar. Sci., 69, 852-863, https://doi.org/10.1093/icesjms/fss056.

Bourke, R. H., J. L. Newton, R. G. Paquette, and M. D. Tunnicliffe, 1987: Circulation and water masses of the East Greenland Shelf. J. Geophys. Res., 92, 6729-6740, https://doi.org/10.1029/ JC092iC07p06729.

Budéus, G., E. Fahrbach, and P. Lemke, 2008: The expedition ARKTIS-XXI/1 a and $b$ of the research vessel "Polarstern" in 2005. Alfred Wegener Institute for Polar and Marine Research Rep. 570, 145 pp., http://epic.awi.de/28681/.

Carmack, E., and Coauthors, 2015: Toward quantifying the increasing role of oceanic heat in sea ice loss in the new Arctic. Bull. Amer. Meteor. Soc., 96, 2079-2105, https://doi.org/ 10.1175/BAMS-D-13-00177.1.

— , and Coauthors, 2016: Freshwater and its role in the Arctic Marine System: Sources, disposition, storage, export, and physical and biogeochemical consequences in the Arctic and global oceans. J. Geophys. Res. Biogeosci., 121, 675-717, https://doi.org/10.1002/2015JG003140.

Cowtan, K., and R. G. Way, 2014: Coverage bias in the HadCRUT4 temperature series and its impact on recent temperature trends. Quart. J. Roy. Meteor. Soc., 140, 1935-1944, https://doi.org/ 10.1002/qj.2297.

Cullather, R. I., and M. G. Bosilovich, 2012: The energy budget of the polar atmosphere in MERRA. J. Climate, 25, 5-24, https://doi.org/10.1175/2011JCLI4138.1.

Curry, B., C. M. Lee, and B. Petrie, 2011: Volume, freshwater, and heat fluxes through Davis Strait, 2004-05. J. Phys. Oceanogr., 41, 429-436, https://doi.org/10.1175/2010JPO4536.1.

,,--- , R. E. Moritz, and R. Kwok, 2014: Multiyear volume, liquid freshwater, and sea ice transports through Davis Strait, 2004-10. J. Phys. Oceanogr., 44, 1244-1266, https://doi.org/10.1175/JPO-D-13-0177.1.

de Steur, L., E. Hansen, R. Gerdes, M. Karcher, E. Fahrbach, and J. Holfort, 2009: Freshwater fluxes in the East Greenland Current: A decade of observations. Geophys. Res. Lett., 36, L23611, https://doi.org/10.1029/2009GL041278.

,$--\frac{1}{-}$ C. Mauritzen, A. Beszczynska-Möller, and E. Fahrbach, 2014: Impact of recirculation on the East Greenland Current in Fram Strait: Results from moored current meter measurements between 1997 and 2009. Deep-Sea Res., 92, 26-40, https://doi.org/ 10.1016/j.dsr.2014.05.018.

Dickson, R., B. Rudels, S. Dye, M. Karcher, J. Meincke, and I. Yashayaev, 2007: Current estimates of freshwater flux through Arctic and subarctic seas. Prog. Oceanogr., 73, 210230, https://doi.org/10.1016/j.pocean.2006.12.003.

Ekwurzel, B., P. Schlosser, R. A. Mortlock, R. G. Fairbanks, and J. H. Swift, 2001: River runoff, sea ice meltwater, and Pacific water distribution and mean residence times in the Arctic Ocean. J. Geophys. Res., 106, 9075-9092, https://doi.org/10.1029/1999JC000024.

Ganachaud, A., and C. Wunsch, 2003: Large-scale ocean heat and freshwater transports during the World Ocean Circulation Experiment. J. Climate, 16, 696-705, https://doi.org/10.1175/ 1520-0442(2003)016<0696:LSOHAF>2.0.CO;2.

Giles, K. A., S. W. Laxon, A. L. Ridout, D. J. Wingham, and S. Bacon, 2012: Western Arctic Ocean freshwater storage increased by wind-driven spin-up of the Beaufort Gyre. Nat. Geosci., 5, 194-197, https://doi.org/10.1038/ngeo1379.

Haine, T. W. N., and Coauthors, 2015: Arctic freshwater export: Status, mechanisms, and prospects. Global Planet. Change, 125, 13-35, https://doi.org/10.1016/j.gloplacha.2014.11.013. 
Ingvaldsen, R. B., L. Asplin, and H. Loeng, 2004: The seasonal cycle in the Atlantic transport to the Barents Sea during the years 1997-2001. Cont. Shelf Res., 24, 1015-1032, https://doi.org/ 10.1016/j.csr.2004.02.011.

Jakobsson, M., 2002: Hypsometry and volume of the Arctic Ocean and its constituent seas. Geochem. Geophys. Geosyst., 3, 1-18, https://doi.org/10.1029/2001GC000302.

Jullion, L., and Coauthors, 2014: The contribution of the Weddell Gyre to the lower limb of the global overturning circulation. J. Geophys. Res. Oceans, 119, 3357-3377, https://doi.org/ 10.1002/2013JC009725.

Kalnay, E., and Coauthors, 1996: The NCEP/NCAR 40-Year Reanalysis Project. Bull. Amer. Meteor. Soc., 77, 437-472, https:// doi.org/10.1175/1520-0477(1996)077<0437:TNYRP>2.0.CO;2.

Karcher, M., A. Beszczynska-Möller, F. Kauker, R. Gerdes, S. Heyen, B. Rudels, and U. Schauer, 2011: Arctic Ocean warming and its consequences for the Denmark Strait overflow. J. Geophys. Res., 116, C02037, https://doi.org/10.1029/ 2010JC006265.

_ _ J. N. Smith, F. Kauker, R. Gerdes, and W. M. Smethie, 2012: Recent changes in Arctic Ocean circulation revealed by iodine-129 observations and modeling. J. Geophys. Res., 117, C08007, https://doi.org/10.1029/2011JC007513.

Korhonen, M., B. Rudels, M. Marnela, A. Wisotzki, and J. Zhao, 2013: Time and space variability of freshwater content, heat content and seasonal ice melt in the Arctic Ocean from 1991 to 2011. Ocean Sci., 9, 1015-1055, https://doi.org/10.5194/os-91015-2013.

Kovacs, A., 1996: Sea Ice. Part 1: Bulk salinity versus ice floe thickness, Cold Regions Research and Engineering Laboratory, 16 pp., http://www.dtic.mil/docs/citations/ ADA312027.

Lammers, R. B., J. W. Pundsack, and A. I. Shiklomanov, 2007: Variability in river temperature, discharge, and energy flux from the Russian pan-Arctic landmass. J. Geophys. Res., 112, G04S59, https://doi.org/10.1029/2006JG000370.

Lindsay, R., and A. Schweiger, 2015: Arctic sea ice thickness loss determined using subsurface, aircraft, and satellite observations. Cryosphere, 9, 269-283, https://doi.org/10.5194/tc-9-2692015.

— M. Wensnahan, A. Schweiger, and J. Zhang, 2014: Evaluation of seven different atmospheric reanalysis products in the Arctic. J. Climate, 27, 2588-2606, https://doi.org/10.1175/ JCLI-D-13-00014.1.

Lique, C., and M. Steele, 2013: Seasonal to decadal variability of Arctic Ocean heat content: A model-based analysis and implications for autonomous observing systems. J. Geophys. Res. Oceans, 118, 1673-1695, https://doi.org/ 10.1002/jgrc.20127.

- - A. M. Treguier, M. Scheinert, and T. Penduff, 2009: A modelbased study of ice and freshwater transport variability along both sides of Greenland. Climate Dyn., 33, 685-705, https:// doi.org/10.1007/s00382-008-0510-7.

,,-- B. Blanke, and N. Grima, 2010: On the origins of water masses exported along both sides of Greenland: A Lagrangian model analysis. J. Geophys. Res., 115, C05019, https://doi.org/ 10.1029/2009JC005316.

Lumpkin, R., and K. Speer, 2003: Large-scale vertical and horizontal circulation in the North Atlantic Ocean. J. Phys. Oceanogr., 33, 1902-1920, https://doi.org/10.1175/1520-0485(2003)033<1902: LVAHCI>2.0.CO;2.

MacGilchrist, G. A., A. C. Naveira Garabato, T. Tsubouchi, S. Bacon, S. Torres-Valdés, and K. Azetsu-Scott, 2014: The
Arctic Ocean carbon sink. Deep-Sea Res., 86, 39-55, https:// doi.org/10.1016/j.dsr.2014.01.002.

Mauldin, A., P. Schlosser, R. Newton, W. M. Smethie Jr., R. Bayer, M. Rhein, and E. P. Jones, 2010: The velocity and mixing time scale of the Arctic Ocean Boundary Current estimated with transient tracers. J. Geophys. Res., 115, C08002, https://doi.org/ 10.1029/2009JC005965.

Mauritzen, C., 1996: Production of dense overflow waters feeding the North Atlantic across the Greenland-Scotland Ridge. Part 2: An inverse model. Deep Sea Res., 43, 807-835, https://doi.org/ 10.1016/0967-0637(96)00038-6.

, and Coauthors, 2011: Closing the loop-Approaches to monitoring the state of the Arctic Mediterranean during the International Polar Year 2007-2008. Prog. Oceanogr., 90, 62-89, https://doi.org/10.1016/j.pocean.2011.02.010.

Mayer, M., L. Haimberger, M. Pietschnig, and A. Storto, 2016: Facets of Arctic energy accumulation based on observations and reanalyses 2000-2015. Geophys. Res. Lett., 43, 10420 10 429, https://doi.org/10.1002/2016GL070557.

McDonagh, E. L. and B.A. King, 2005: Oceanic fluxes in the South Atlantic. J. Phys. Oceanogr., 35, 109-122, https://doi.org/ 10.1175/JPO-2666.1.

McIntosh, P. C., and S. R. Rintoul, 1997: Do box inverse models work? J. Phys. Oceanogr., 27, 291-308, https://doi.org/10.1175/ 1520-0485(1997)027<0291:DBIMW>2.0.CO;2.

McPhee, M. G., 2013: Intensification of geostrophic currents in the Canada Basin, Arctic Ocean. J. Climate, 26, 3130-3138, https:// doi.org/10.1175/JCLI-D-12-00289.1.

—, A. Proshutinsky, J. H. Morison, M. Steele, and M. B. Alkire, 2009: Rapid change in freshwater content of the Arctic Ocean. Geophys. Res. Lett., 36, L10602, https://doi.org/ 10.1029/2009GL037525.

Morgan, P. P., 1995: Box inverse modelling with DOBOX 4.2., CSIRO Marine Laboratories Rep. 225, 26 pp., http://www.cmar.csiro.au/ e-print/open/CMReport_225.pdf.

National Geophysical Data Center, 2006: 2-minute Gridded Global Relief Data (ETOPO2) v2. National Geophysical Data Center, accessed October 2017, https://doi.org/10.7289/ V5J1012Q.

Naveira Garabato, A. C., D. P. Stevens, and K. J. Heywood, 2003: Water mass conversion, fluxes, and mixing in the Scotia Sea diagnosed by an inverse model. J. Phys. Oceanogr., 33, 2565-2587, https://doi.org/10.1175/1520-0485(2003)033<2565: WMCFAM $>2.0 . \mathrm{CO} ; 2$.

Ono, N., 1967: Specific heat and heat of fusion of sea ice. Physics of Snow and Ice, H. Oura, Ed., Institute of Low Temperature Science, Hokkaido, Japan, 599-610.

Overeem, I., and J. P. M. Syvitski, 2010: Shifting discharge peaks in Arctic rivers, 1977-2007. Geograf. Ann., 92a, 285-296, https:// doi.org/10.1111/j.1468-0459.2010.00395.x.

Pemberton, P., J. Nilsson, M. Hieronymus, and H. E. M. Meier, 2015: Arctic Ocean water mass transformation in $S-T$ coordinates. J. Phys. Oceanogr., 45, 1025-1050, https://doi.org/ 10.1175/JPO-D-14-0197.1.

Polyakov, I. V., and Coauthors, 2011: Fate of early 2000s Arctic warm water pulse. Bull. Amer. Meteor. Soc., 92, 561-566, https://doi.org/10.1175/2010BAMS2921.1.

, A. V. Pnyushkov, and L. A. Timokhov, 2012: Warming of the Intermediate Atlantic Water of the Arctic Ocean in the 2000s. J. Climate, 25, 8362-8370, https://doi.org/10.1175/JCLI-D-12-00266.1. , and Coauthors, 2017: Greater role for Atlantic inflows on seaice loss in the Eurasian Basin of the Arctic Ocean. Science, 356, 285-291, https://doi.org/10.1126/science.aai8204. 
Porter, D. F., J. J. Cassano, M. C. Serreze, and D. N. Kindig, 2010: New estimates of the large-scale Arctic atmospheric energy budget. J. Geophys. Res., 115, D08108, https://doi.org/10.1029/ 2009JD012653.

Proshutinsky, A., and Coauthors, 2009: Beaufort Gyre freshwater reservoir: State and variability from observations. J. Geophys. Res., 114, C00A10, https://doi.org/10.1029/2008JC005104.

Rabe, B., U. Schauer, A. Mackensen, M. Karcher, E. Hansen, and A. Beszczynska-Möller, 2009: Freshwater components and transports in the Fram Strait-Recent observations and changes since the late 1990s. Ocean Sci., 5, 219-233, https:// doi.org/10.5194/os-5-219-2009.

— storage trend 1992-2012. Geophys. Res. Lett., 41, 961-968, https://doi.org/10.1002/2013GL058121.

Rippeth, T. P., B. J. Lincoln, Y. D. Lenn, J. A. M. Green, A. Sundfjord, and S. Bacon, 2015: Tide-mediated warming of Arctic halocline by Atlantic heat fluxes over rough topography. Nat. Geosci., 8, 191-194, https://doi.org/10.1038/ngeo2350.

Saha, S., and Coauthors, 2010: The NCEP Climate Forecast System Reanalysis. Bull. Amer. Meteor. Soc., 91, 1015-1057, https:// doi.org/10.1175/2010BAMS3001.1.

Schaffer, J., W. J. von Appen, P. A. Dodd, C. Hofstede, C. Mayer, L. de Steur, and T. Kanzow, 2017: Warm water pathways toward Nioghalvfjerdsfjorden Glacier, Northeast Greenland. J. Geophys. Res. Oceans, 122, 4004-4020, https://doi.org/ 10.1002/2016JC012462.

Schauer, U., and A. Beszczynska-Möller, 2009: Problems with estimation and interpretation of oceanic heat transport-Conceptual remarks for the case of Fram Strait in the Arctic Ocean. Ocean Sci., 5, 487-494, https://doi.org/10.5194/os-5487-2009.

, E. Fahrbach, S. Osterhus, and G. Rohardt, 2004: Arctic warming through the Fram Strait: Oceanic heat transport from 3 years of measurements. J. Geophys. Res., 109, C06026, https://doi.org/10.1029/2003JC001823.

, A. Beszczynska-Möller, W. Walczowski, E. Fahrbach, J. Piechura, and E. Hansen, 2008: Variation of measured heat flow through the Fram Strait between 1997 and 2006. ArcticSubarctic Ocean Fluxes: Defining the Role of the Northern Seas in Climate, R. R. Dickson, J. Meincke, and P. Rhines, Eds., Springer, 65-85.

Schlosser, P., and Coauthors, 1999: Pathways and mean residence times of dissolved pollutants in the ocean derived from transient tracers and stable isotopes. Sci. Total Environ., 237-238, 15-30, https://doi.org/10.1016/S0048-9697(99)00121-7.

Schweiger, A., R. Lindsay, J. L. Zhang, M. Steele, H. Stern, and R. Kwok, 2011: Uncertainty in modeled Arctic sea ice volume. J. Geophys. Res., 116, C00D06, https://doi.org/10.1029/ 2011JC007084.

Serreze, M. C., and Coauthors, 2006: The large-scale freshwater cycle of the Arctic. J. Geophys. Res., 111, C11010, https://doi.org/ 10.1029/2005JC003424.

— M. M. Holland, and J. Stroeve, 2007a: Perspectives on the Arctic's shrinking sea-ice cover. Science, 315, 1533-1536, https://doi.org/10.1126/science.1139426.

—, A. P. Barrett, A. G. Slater, M. Steele, J. Zhang, and K. E. Trenberth, 2007b: The large-scale energy budget of the Arctic. J. Geophys. Res., 112, D11122, https://doi.org/10.1029/ 2006JD008230.

, - - J. C. Stroeve, D. N. Kindig, and M. M. Holland, 2009: The emergence of surface-based Arctic amplification. Cryosphere, 3, 11-19, https://doi.org/10.5194/tc-3-11-2009.
J. Stroeve, A. P. Barrett, and L. N. Boisvert, 2016: Summer atmospheric circulation anomalies over the Arctic Ocean and their influences on September sea ice extent: A cautionary tale. J. Geophys. Res., 121, 11463-11485, https://doi.org/ 10.1002/2016JD025161.

Shiklomanov, A. I., and R. B. Lammers, 2009: Record Russian river discharge in 2007 and the limits of analysis. Environ. Res. Lett., 4, 045015, https://doi.org/10.1088/1748-9326/4/4/ 045015 .

$\longrightarrow$, and — 2014: River ice responses to a warming ArcticRecent evidence from Russian rivers. Environ. Res. Lett., 9, 035008, https://doi.org/10.1088/1748-9326/9/3/035008.

Shokr, M., and N. Sinha, 2015: Sea Ice: Physics and Remote Sensing. Geophys. Monogr., Vol. 209, Amer. Geophys. Union, $600 \mathrm{pp}$.

Smedsrud, L. H., R. Ingvaldsen, J. E. O. Nilsen, and O. Skagseth, 2010: Heat in the Barents Sea: Transport, storage, and surface fluxes. Ocean Sci., 6, 219-234, https://doi.org/10.5194/ os-6-219-2010.

Smolin, V., F. Guskov, T. Gromnickiy, S. Pavlov, and K. Khomenja, 2006: The joint Russian-American Long-term Census of the Arctic (RUSALCA) cruise report during 23-30 August 2006. RUSALCA Rep., 6 pp., https://www.pmel.noaa.gov/ rusalca/sites/default/files/atoms/files/CruiseReport.pdf.

Spreen, G., S. Kern, D. Stammer, and E. Hansen, 2009: Fram Strait sea ice volume export estimated between 2003 and 2008 from satellite data. Geophys. Res. Lett., 36, L19502, https://doi.org/ 10.1029/2009GL039591.

Steele, M., and T. Boyd, 1998: Retreat of the cold halocline layer in the Arctic Ocean. J. Geophys. Res., 103, 10 419-10 435, https:// doi.org/10.1029/98JC00580.

Talley, L. D., 2003: Shallow, intermediate, and deep overturning components of the global heat budget. J. Phys. Oceanogr., 33, 530-560, https://doi.org/10.1175/1520-0485(2003)033<0530: SIADOC $>2.0 . \mathrm{CO} ; 2$.

_ 2008: Freshwater transport estimates and the global overturning circulation: Shallow, deep and throughflow components. Prog. Oceanogr., 78, 257-303, https://doi.org/10.1016/ j.pocean.2008.05.001.

Topp, R., and M. Johnson, 1997: Winter intensification and water mass evolution from yearlong current meters in the Northeast Water Polynya. J. Mar. Syst., 10, 157-173, https://doi.org/ 10.1016/S0924-7963(96)00083-8.

Torres-Valdés, S., and Coauthors, 2013: Export of nutrients from the Arctic Ocean. J. Geophys. Res. Oceans, 118, 1625-1644, https://doi.org/10.1002/jgrc.20063.

— T. Tsubouchi, E. Davey, I. Yashayaev, and S. Bacon, 2016: Relevance of dissolved organic nutrients for the Arctic Ocean nutrient budget. Geophys. Res. Lett., 43, 6418-6426, https:// doi.org/10.1002/2016GL069245.

Tsubouchi, T., and Coauthors, 2012: The Arctic Ocean in summer: A quasi-synoptic inverse estimate of boundary fluxes and water mass transformation. J. Geophys. Res., 117, C01024, https://doi.org/10.1029/2011JC007174.

Uppala, S. M., and Coauthors, 2005: The ERA-40 Re-Analysis. Quart. J. Roy. Meteor. Soc., 131, 2961-3012, https://doi.org/10.1256/qj.04.176.

Vihma, T., and Coauthors, 2016: The atmospheric role in the Arctic water cycle: A review on processes, past and future changes, and their impacts. J. Geophys. Res., 121, 586-620, https://doi.org/ 10.1002/2015JG003132.

Walin, G., 1982: On the relation between sea-surface heat-flow and thermal circulation in the ocean. Tellus, 34, 187-195, https:// doi.org/10.3402/tellusa.v34i2.10801. 
Woodgate, R. A., 2006: Cruise Report for CCGS Sir Wilfrid Laurier 0-SWL2006-01, 1-9 July 2006, 13 pp., http://psc.apl.washington.edu/ HLD/SWL2006/UWmooringreportSWL2006July.pdf.

- and K. Aagaard, 2005: Revising the Bering Strait freshwater flux into the Arctic Ocean. Geophys. Res. Lett., 32, L02602, https://doi.org/10.1029/2004GL021747.

- _ - and T. J. Weingartner, 2005: Monthly temperature, salinity, and transport variability of the Bering Strait through flow. Geophys. Res. Lett., 32, L04601, https://doi.org/10.1029/ 2004GL021880.
— , T. Weingartner, and R. Lindsay, 2010: The 2007 Bering Strait oceanic heat flux and anomalous Arctic sea-ice retreat. Geophys. Res. Lett., 37, L01602, https://doi.org/10.1029/2009GL041621.

Wunsch, C., 1978: The North Atlantic general circulation west of $50^{\circ} \mathrm{W}$ determined by inverse methods. Rev. Geophys., 16, 583-620, https://doi.org/10.1029/RG016i004p00583.

Zhang, J. L., and D. A. Rothrock, 2003: Modeling global sea ice with a thickness and enthalpy distribution model in generalized curvilinear coordinates. Mon. Wea. Rev., 131, 845-861, https://doi.org/ 10.1175/1520-0493(2003)131<0845:MGSIWA>2.0.CO;2. 